\title{
WestVirginiaUniversity
}

THE RESEARCH REPOSITORY @ WVU

Graduate Theses, Dissertations, and Problem Reports

2012

\section{Examining the Forces Associated with Heading in Collegiate Soccer Athletes}

\author{
Elizabeth A. Tenore \\ West Virginia University
}

Follow this and additional works at: https://researchrepository.wvu.edu/etd

\section{Recommended Citation}

Tenore, Elizabeth A., "Examining the Forces Associated with Heading in Collegiate Soccer Athletes" (2012). Graduate Theses, Dissertations, and Problem Reports. 650.

https://researchrepository.wvu.edu/etd/650

This Thesis is protected by copyright and/or related rights. It has been brought to you by the The Research Repository @ WVU with permission from the rights-holder(s). You are free to use this Thesis in any way that is permitted by the copyright and related rights legislation that applies to your use. For other uses you must obtain permission from the rights-holder(s) directly, unless additional rights are indicated by a Creative Commons license in the record and/ or on the work itself. This Thesis has been accepted for inclusion in WVU Graduate Theses, Dissertations, and Problem Reports collection by an authorized administrator of The Research Repository @ WVU. For more information, please contact researchrepository@mail.wvu.edu. 
Examining the Forces Associated with Heading in Collegiate Soccer Athletes

Elizabeth A. Tenore, BS, ATC

Thesis submitted to the

College of Physical Activity and Sport Sciences

at West Virginia University

in partial fulfillment of the requirements

for the degree of

Master of Science

in

Athletic Training

\section{Michelle A. Sandrey, Ph.D., ATC, Chair}

Victor H. Mucino, Ph. D.

Benjamin Moorehead, MD

College of Physical Education and Sport Sciences

Morgantown, WV

2012

Keywords: biomechanics, concussion, heading, soccer 


\begin{abstract}
Examining the Forces Associated with Heading in Collegiate Soccer Athletes
\end{abstract}

Elizabeth A. Tenore, BS, ATC

Context: Repetitive sub-concussive impacts have recently been recognized as a contributing factor of long-term cognitive deficits. The potential for this to affect soccer players participating at a high level is great due to the constant intentional use of the unprotected head when playing. Examining the force with which a soccer ball strikes an athlete's head during the act of heading is important to determine if there is a potential risk for long term consequences. Objective: The purpose of this study was to determine how much force is associated with heading in soccer. The variability between goal and corner kicks and throw-ins were examined. A secondary purpose was to determine if this information is indicative of soccer players potentially being at risk due to repetitive subconcussive impacts. Design: This was a prospective descriptive study which examined the forces transferred from a soccer ball to the head during simulated soccer heading scenarios. Setting: Collegiate soccer conditions in the Mid-Atlantic part of the country. Patients and Other Participants: Using a sample of convenience, three male collegiate soccer players between the ages of 19-22 playing at a D1 level at the time of the study were used. Subjects were selected if they headed the ball five or more times in a game, had five or more years of playing experience at the time of the study and had not had any head or neck injuries in the six months preceding the study. Interventions: Each subject went through a series of 3 different heading scenarios, heading the ball 5 times for each scenario. Heading was done with goal kicks, corner kicks and throw-ins. Pressure film on the subjects' head recorded the force during the act of heading. Film was changed following each header and then sent to the lab for analysis. The analysis included minimum, maximum and average pressure. Main Outcome Measures: The forces recorded with heading the soccer ball during all three heading scenarios will be comparable to the numbers seen with football and ice hockey players. The forces seen with a goal kick will be higher on average than those recorded with corner kicks and throw-ins. Results: Ball speeds were found to range from $26-57 \mathrm{mph}$ across 42 trials of three different heading scenarios. Goal kicks were found to produce the highest speeds and forces recorded with throw-in's produced the lowest speeds and forces. Forces ranged from $364.34 \mathrm{lbf}-1070.18 \mathrm{lbf}$. Conclusions: Current research suggests that while the forces acting on the head during heading are below the accepted value for concussion there is still a risk for cumulative damage secondary to repetitive impacts sustained at sub-concussive levels. Further examination of duration of impact, acceleration/deceleration of the head and cognitive testing in former players who were considered headers is suggested to better understand the risk posed by repetitive heading. 


\section{ACKNOWLEDGEMENTS}

\section{Philippians 4:13}

For my parents without whom furthering my education would not have been possible. Your unconditional love and support has allowed me to "go confidently in the direction of my dreams". I would not be where I am today nor achieved what I have if it was not

for your belief in me.

To Katie and Jackie

"Life made us sisters but love has made us best friends"

A girl could not have asked for two better sisters to share life's crazy up's and down's with and I am so blessed and proud that you are mine.

To my family

No matter the distance or time I know I will always have somewhere to go where I will be welcomed with love and open arms. You have all had a profound impact on me and I will be forever grateful.

To Shane

This "girl in the corner" is so lucky that you have come into her life. Thank you for believing in me, supporting me, and loving me. I would not have been able to get through this process if it wasn't for you. This crazy ride is just getting started and I wouldn't want to be on it with anyone else.

To Dr. Sandrey

Thank you for your support and guidance both through graduate school and the writing of this thesis. Your dedication to your students is unparalleled and I am grateful for your help.

To Dr. Moorehead

Thank you for not only serving on my committee but for all that I learned from you during my time at WVU. I cannot express how much your belief in this study means to

me.

To Dr. Mucino

Thank you for agreeing to be on my committee without knowing me or knowing what I wanted to do. You made my idea a possibility and made the scary world of physics, well, not so scary.

To Brittany

You have been a great mentor and an even better friend. You were always there to provide the theoretical slap in the face or a welcomed escape depending on what the situation warranted and for that I am thankful. 


\section{To Snooks}

My Jersey connection! From the Garden State to W. Va. to Buffalo. Can't wait to see where we end up next!

To my classmates

You've made the daunting task of grad school more fun than I would have ever imagined it to be and I wish you the best of luck as we all move forward from here.

To the T4L crew

Thank you for taking the time to make this study possible. As for the rest...there are no words so I'll just say prayers for you. 


\section{TABLE OF CONTENTS}

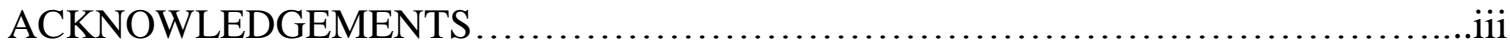

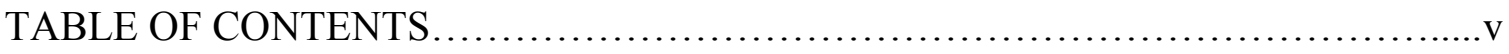

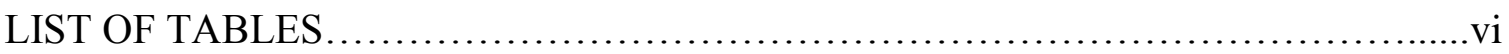

LIST OF FIGURES ...........................................................

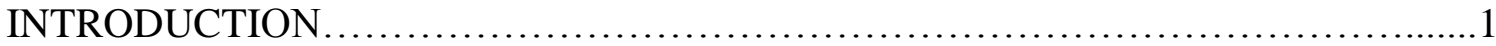

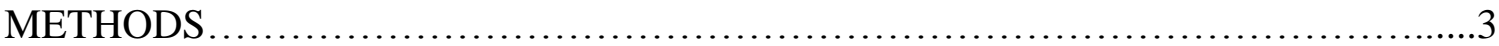

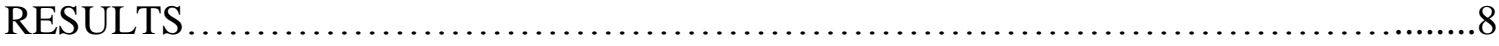

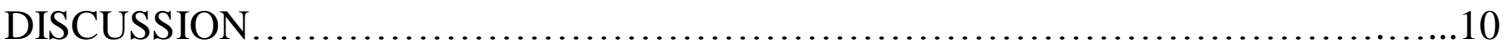

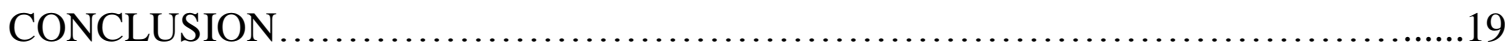

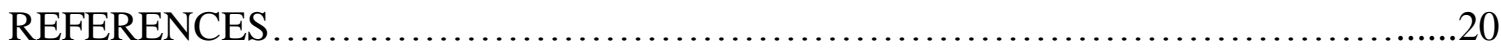

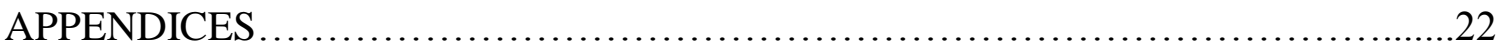

APPENDIX A. THE PROBLEM........................................23

APPENDIX B. LITERATURE REVIEW ................................29

APPENDIX C. ADDITIONAL METHODS ................................41

APPENDIX D. ADDITIONAL RESULTS ..................................51

APPENDIX E. RECOMMENDATIONS FOR FUTURE RESEARCH...........60

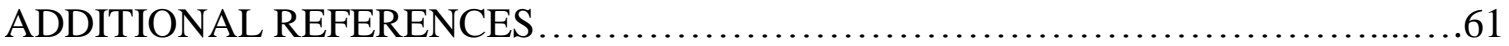




\section{LIST OF TABLES}

Table

Page

Table C1. Informed Consent................................................... 41

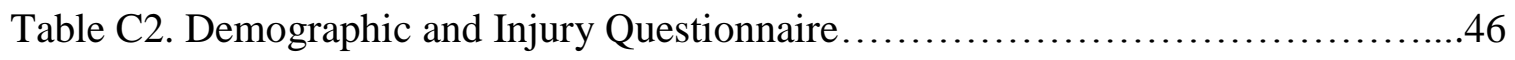

Table D1. Subject 1 Results for the Three Heading Scenarios............................52

Table D2. Subject 2 Results for the Three Heading Scenarios..........................53

Table D3. Subject 3 Results for the Three Heading Scenarios.............................54 


\section{LIST OF FIGURES}

Table

Page

Figure C1. Pressure Film Preparation..........................................47

Figure C2. Pressure Film Application.........................................48

Figure C3. Goal Kick.......................................................49

Figure C4. Corner Kick ...................................................50

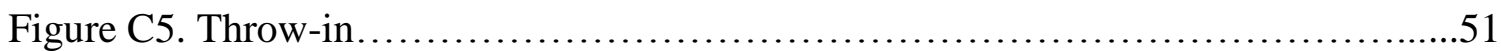

Figure D1. Corner Kick Results...........................................55

Figure D2. Throw-in Results.................................................56

Figure D3. Goal Kick Results.............................................57

Figure D4. Ball Speed Results ................................................58

Figure D5. Recorded Force Results.........................................59 


\section{INTRODUCTION}

Concussions are defined as "complex pathophysiological process affecting the brain, induced by traumatic biomechanical forces." The topic of concussions in sport and consequences of repetitive hits has become one of the most popular topics in both the athletic and medical communities. While the majority of the studies are conducted on football and ice hockey players, more research is starting to emerge that examines the act of heading in soccer. Due to the unique nature of the act of heading, where an athlete intentionally strikes a ball travelling at speeds upwards of $40 \mathrm{mph}$ with an unprotected head, concerns are being raised about the possible detrimental effects this may have on long-term cognitive and behavioral function.

Concussions in sport result from two main mechanisms. The first being acceleration-deceleration forces which are linear in nature. ${ }^{2}$ The second mechanism is rotational or angular forces which lead to shearing forces acting on the brain. ${ }^{2}$ Rotational mechanisms seem to be the cause of most concussions found in sport. ${ }^{3}$ Accelerationdeceleration injuries lead to contusive trauma on the brain because the brain makes forceful contact with the rigid interior surface of the skull. ${ }^{4}$ Shearing forces caused by the stretching or twisting of the brain tissue can lead to tearing of the axons and potentially the vascular structures. ${ }^{2,4}$

The mechanism of most concussions in soccer occurs during the process of heading. More specifically accidental head to head contact during the act of heading or attempting to head the ball followed by head to body and head to ground contact. ${ }^{5,6}$ It is rare that intentional head to ball contact results in a concussion. ${ }^{4-7}$ Heading is a common act in the game of soccer and every time that an athlete heads or attempts to head the ball 
there is potential for a concussion to occur. Despite the number of opportunities for concussions, overall a very small percentage of the total injuries sustained are while playing. ${ }^{4,8,9}$

Concussions accounted for approximately $7 \%$ of all game injuries sustained in men's college soccer in the US in one year. ${ }^{9,10}$ This percentage is higher than the $3.9 \%$ sustained by boys playing at the high school level. ${ }^{4,9}$ Goalies seemed to be most at risk for sustaining a concussion and this has been attributed to the demands of their position. ${ }^{6}$ Goalies are unique as they are the only players allowed to use their hands without incurring a penalty. Diving head first or running out to meet an opponent in an attempt to stop a ball from going into the goal is not uncommon. It places the goalie in a situation where they may get kicked, stepped on, collide with other players or even hit the post of the goal.

Due to the recent categorization of soccer as a high impact sport, questions are being raised about the occurrence of sub-concussive impacts during the act of heading. Studies have shown that in some instances the force of impacts sustained during the act of head to ball contact is greater than that sustained by a football or ice hockey player taking a hit. ${ }^{9,10,11}$ While these impacts do not necessarily lead to the production of concussive symptoms the question has been raised about the extent of the effect, if any, on the brain.

Studies $^{12,13}$ have been conducted that examine the immediate short-term effects and possible long-term effects that repetitive heading has on neuropsychologic function. The results have shown that impaired cognitive function, as well as structural changes, are much more prevalent in players who were deemed "headers" during the course of 
their careers. However, it is not known if these repetitive sub-concussive impacts and their effects accumulate over time and lead to behavioral and cognitive changes such as those evident in other high-impact sports with similar incidences of hits to the head. This is a multifaceted subject and one that requires extensive research to answer. Thus, this study attempted to address one part by quantifying the short term effects in regard to forces associated with three common heading scenarios in subjects who were deemed "headers". Therefore, the purpose of this study was to determine how much force is associated with heading in soccer. The variability between goal and corner kicks and throw-ins were examined. A secondary purpose was to determine if that information is indicative of soccer players being at risk due to repetitive sub-concussive impacts.

\section{METHODS}

Design

The design of this study was a descriptive analysis to examine force transferred from a soccer ball to the head during the act of heading in three different game-like situations. The heading scenarios were goal kick, corner kick and throw-in. The analysis also examined which type of heading scenario produced the most force. Three male collegiate soccer players were outfitted with pressure sensitive film on their heads and then headed the ball five times at three different stations. The ball was kicked or thrown by a fourth male collegiate soccer player. The film was changed in between each header. After all headers were performed satisfactorily the film was sent to a lab to be analyzed for minimum, maximum and average forces sustained. The speed of the ball was measured using a radar gun. 


\section{Participants}

The participants were male collegiate soccer players who were playing at a DI university in the Mid-Atlantic part of the country at the time the study took place. There were four athletes between the ages of 19-22 who had played soccer for a minimum of 5 years at the time of the study. The participants, using a sample of convenience, were those who were considered "headers" and headed the ball a minimum of five times in a game. The participants were excluded if they had a head or neck injury in the 6 months prior to the study, or any injury (upper or lower extremity) at the time of the study that could effectively reduce the force of the heading. This study was approved by the institution's Office of Research Compliance.

Instrumentation

The pressure sensitive film (Sensor Products, Inc., Madison, NJ) was Ultra-Low film with a calibrated range of 28-85 PSI. Pressure sensitive film is an effective way to measure peak contact pressures between two surfaces. ${ }^{14}$ The film works using a contact sheet and a developer sheet. The contact sheet contains microscopic capsules filled with ink. When pressure is applied the capsules burst and the ink is transferred onto the developer sheet. When the two sheets are pulled apart the image is left on the developer sheet, which is then analyzed in the lab. Despite standard calibration curves that accompany the pressure film, the accuracy is limited to $\pm 5 \%$. This is due to variations during the manufacturing of the pressure film.

The radar gun used was a JUGS Gun (JUGS Sports, Tualatin, OR) with an accuracy index of $\pm .5 \mathrm{mph}$. The radar gun had a speed range of 5-140 mph and a measuring distance of up to 300 feet. Human error when operating the radar gun should 
be taken into consideration and may have resulted in inaccurate recordings of ball speed for this study in addition to the gun's accuracy of $\pm .5 \mathrm{mph}$. To avoid this calibration following the manufacturers' guidelines should be completed prior to data collection. A Nike Catalyst soccer ball (Nike, Inc., Beaverton, OR) was used as it was the ball used at this institute and the most readily available. The ball was a Size 5, which weighs between 14-16 ounces (about $1 \mathrm{lb}$.). This is the standard size for collegiate soccer balls. The outer shell of the ball consisted of $44 \%$ rubber, $28 \%$ polyurethane, $26 \%$ polyester and $2 \%$ cotton. FIFA rules regulate game ball pressure to be $8.5-15.6 \mathrm{lbs} / \mathrm{in}^{2}$; the ball used in this study was filled to $10.5-11.0 \mathrm{lbs} / \mathrm{in}^{2}$. Procedures

Subjects were asked to voluntarily participate in the study. If they agreed they were asked to read and sign an informed consent (Table $\mathrm{C} 1$ ) as well as complete a demographic and injury questionnaire (Table $\mathrm{C} 2$ ) prior to participation. The demographic and injury questionnaire included questions about how many years the participant had been playing soccer, an estimate of how many times they headed the ball, injuries they may have had in the last 6 months and any concussions they may have had. This information was used to determine if the participant was eligible for the study. Subjects were admitted into the study if they voluntarily agreed to be and met the inclusion criteria stated above.

The film was cut so as to cover the participants' head from mid-forehead to just behind the ears. (Figure C1-2) The film was wrapped in plastic wrap prior to fixation, as it is sensitive to sweat and dirt. (Figure C-1) The film was changed after each header the subject performed. The order of the kicks was randomized so that each participant was 
first for a different heading scenario. Prior to heading the subjects were instructed to warm-up for about 10 minutes. The warm-up included jogging 2 laps around the soccer field and stretching the lower extremity using the stretching routine normally completed before practices and games.

The first heading scenario was corner kicks. The order of the subjects was 1,2, and 3. The second heading scenario performed was throw-ins. Subject 2 started, followed by Subject 3 and Subject 1. Lastly, goal kicks were performed and initiated by Subject 3, then Subject 1 and Subject 2. The subjects rotated following every header. This allowed for a better transition when removing and changing the pressure film.

For goal kicks the kicking subject stood at one goal while the heading subject stood at mid-field (Figure C3). The kicker kicked the ball down field and the header headed the ball just as they would in a game. In order to mimic a game-like heading situation the players were told to head the ball however they wanted as there is variability in heading during a game. Variations included directing the ball to another teammate, trying to score a goal and trying to defend the goal.

For corner kicks, the kicker stood at one of the corners and the header stood in front of the goal facing the kicker (Figure C4). The kicker struck the ball so as to serve it to the header who headed the ball as they would in a game.

To examine the forces associated with a throw-in the kicker threw the ball towards the header as they would in a game. The header stood 15 yards away and headed the ball (Figure C5).

Each subject headed the ball 5 times for each scenario (5 corner kicks, 5 goal kicks and 5 throw-ins) for a total of 15 heading opportunities per subject. The kicker 
performed 15 kicks at each of the corner and goal kick stations for a total of 30 kicks. He threw the ball 15 times at the throw-in station.

The speed of the ball for each header was recorded by standing behind the heading subject and facing the kicking subject. The radar gun was aimed at the soccer ball and the reading was taken just after the ball was kicked or thrown-in. This was to try to get a true reading of the ball and not the kicking subjects' body movement as they sent the ball towards the heading subject.

Data Analysis

The film analysis equipment, Topaq ${ }^{\circledR}$ Pressure Analysis System, was rented from the lab at Sensor Products, Inc. (Madison, NJ) and analyzed. The Windows based program and scanner had to be installed on the computer. The developer sheet of the film was placed on the scanner where the image was scanned. Once the image was uploaded to the software on the computer, the temperature and humidity were entered and the image was converted to color to display pressure.

After the image was displayed in color it was analyzed. The results were displayed in the form of computerized data that included a color scale (based on pressure distribution) image, notes on maximum and minimum pressure, average pressure and the contact area. The force was reported using lbf (pounds of force) as the unit and the pressure was reported using PSI (pounds per square inch) as the unit. The data revealed any correlations and showed the red scale that indicated where the pressure was greatest.

Momentum $\left(\mathrm{lb} / \mathrm{in}^{2}\right)$ was calculated using the formula: Force $(\mathrm{lbf}) *$ Delta $\mathrm{T}(\mathrm{s})=$ Mass of the ball (lb) * Velocity (mph). Kinetic energy was also calculated using the formula: Kin. Energy $=1 / 2 *$ mass $*$ velocity $^{2}$ 


\section{RESULTS}

There were a total of 42 headers performed overall by 3 subjects ( 14 each). The fifth goal kick-heading scenario was eliminated for all subjects as 3 pieces of pressure film were not usable. The decision to eliminate the fifth header for goal kicks was based on the last heading scenario performed.

\section{Demographic Characteristics}

The average age of the 4 subjects who participated in the study was $21 \pm 1$ yrs. One hundred percent $(n=4)$ were male. In addition, one hundred percent $(n=4)$ were in their senior year of college. Fifty percent $(n=2)$ of the subjects were center backs, twenty-five percent $(n=1)$ were offensive midfielders and the remaining twenty-five percent $(n=1)$ were center midfielders. The average years of playing experience was 13.5 \pm 3.5 yrs. while the average years heading was $10.75 \pm 2.25$ years. The average estimation of headers per game and/or practice was $11.75 \pm 28.25$.

Injury Questionnaire

One hundred percent $(n=4)$ of the subjects reported having no upper, lower, head or neck injuries in the six months prior to the study. Individual Variations

There were no obvious similarities among the results produced by any of the headers. If the biomechanics of the heading style was examined it is possible there may have been similarities and differences observed between each subject. Another reason that no comparison can be made among heading subjects is because the speed of the ball was determined by the kicking subject. There was some consistency noted with the kicking subject, but only based on the scenario, not individual trials. Throw-in's were 
consistently the lowest, with corner kicks producing moderate forces and goal kicks producing the highest forces, relatively speaking. Among each scenario there was a moderate fluctuation in speeds. (Table D1-3)

\section{Corner Kicks}

The average speed for the corner kicks was $43.3 \mathrm{mph} \pm 11.7 \mathrm{mph}$. The minimum speed recorded for corner kicks was $37 \mathrm{mph}$ while the maximum speed was $55 \mathrm{mph}$. Sixty percent $(n=9)$ of the corner kicks were below the average speed while only forty percent $(n=6)$ were above it. The average force of the corner kick was $693.2 \pm 325.01$ lbf. The minimum and maximum forces recorded were $470.36 \mathrm{lbf}$ and 1,018.21, respectively. Seventy-three percent $(n=11)$ of the corner kicks imparted a force below the average leaving only twenty-seven percent $(n=14)$ above. The average momentum was $1.97 \pm .55 \mathrm{lb} / \mathrm{in}^{2}$. The minimum and maximum momentums were 1.70 and $2.52 \mathrm{lb} / \mathrm{in}^{2}$. The average duration of impact was $2.98 \pm 1.10 \mathrm{~ms}$, with the minimum and maximum being $1.89 \mathrm{~ms}$ and $3.97 \mathrm{~ms}$ respectively. (Figure D1)

Throw-In's

The average speed of throw-in's was $28.5 \pm 2.5 \mathrm{mph}$. Both minimum and maximum speeds were much lower than the corner kicks or goal kicks as was expected. The minimum speed recorded was $26 \mathrm{mph}$ and the maximum speed was $31 \mathrm{mph}$. Average force recorded for this heading scenario was $582.8 \pm 236.46 \mathrm{lbf}$. The minimum force was $346.34 \mathrm{lbf}$ while the maximum force was $771.59 \mathrm{lbf}$. Only twenty percent $(n=3)$ of the throw-ins were below $28.5 \mathrm{mph}$. The remaining sixty percent $(n=12)$ were above the calculated average speed. With regard to the forces recorded, fifty-three percent $(n=8)$ were below the average recorded force of $582.8 \mathrm{lbf}$ and forty-seven percent 
$(n=7)$ were above. While there were far less throw-in's below the average speed the number of throw-in's above and below the average force are almost equal. The average momentum was $1.29 \pm .13 \mathrm{lb} / \mathrm{in}^{2}$. The minimum and maximum momentums were 1.28 and $1.42 \mathrm{lb} / \mathrm{in}^{2}$. The average duration of impact was $2.33 \pm 1.63 \mathrm{~ms}$, with the minimum and maximum being $1.72 \mathrm{~ms}$ and $3.96 \mathrm{~ms}$ respectively (Figure D2)

\section{Goal Kicks}

The average speed of goal kicks was $46.7 \pm 10.3 \mathrm{mph}$. Minimum and maximum speeds were 38 and $57 \mathrm{mph}$, respectively. Twenty-seven percent $(\mathrm{n}=4)$ were below the average speed and seventy-three percent $(n=11)$ were above. The average force recorded was $809.7 \pm 308.22 \mathrm{lbf}$. This kicking scenario produced a minimal force of $501.48 \mathrm{lbf}$ and a maximum force of 1,070.78 lbf. Forty percent $(n=6)$ headers from goal kicks yielded a force below the average leaving sixty percent $(n=9)$ above it. The goal kick trials not only produced the header with the highest speed but also the highest force recorded, though not on the same trial. Conversely, the trial with one of the lowest speeds for goal kicks produced the highest recorded force while the trial with the highest speed produced the second lowest force. The average momentum was $2.13 \pm .48 \mathrm{lb} / \mathrm{in}^{2}$. The minimum and maximum momentums were 1.74 and $2.61 \mathrm{lb} / \mathrm{in}^{2}$. The average duration of impact was $2.77 \pm 1.15 \mathrm{~ms}$, with the minimum and maximum being $1.62 \mathrm{~ms}$ and 4.19 ms. respectively (Figure D3)

\section{DISCUSSION}

The primary purpose of this study was to quantify and examine the forces that occur when a soccer ball makes contact with the head during the act of heading. Forces that occur with ball to head impact only account for one aspect of head injury with head 
acceleration-deceleration, rotational mechanisms, impact attenuation and injury threshold accounting for the rest. The secondary purpose of this study sought to use the information gathered and determine if it is indicative of soccer players being at risk for long term cognitive deficit due to repetitive sub-concussive impacts. This was to be determined by comparing the current literature surrounding the forces deemed as concussive as well as sub-concussive.

There were 3 hypotheses for this study. All three hypotheses were rejected as corner kicks did not produce greater forces, forces were different between and within each player and distance the ball traveled did not have an effect on the forces recorded with longer distances producing less force. It was noted that the player who was the most aggressive in attacking the ball and moving faster to the ball to head (Subject 3) recorded the most variability, while subjects 1 and 2 were fairly close in forces recorded throughout the five trials of the three scenarios. As this is the first study to evaluate heading forces during goal kicks, corner kicks and throw-in scenarios in a non-controlled environment, there are no known comparisons with other studies in the literature. However, this study produced heading force and velocities higher than that reported in the literature for corner and goal kicks ${ }^{15}$ that require further verification studies. Variations Between the Three Heading Scenarios

Overall, corner kicks produced forces greater than throw-in's but goal kicks produced the highest forces. Corner kicks are involved in a heading scenario where the objective of the team serving the ball is to score a goal. If the ball is kicked too hard it is not considered a viable header. Additionally, the ball does not need to travel as far a 
distance as it would with a goal kick so the kicker need not strike the ball as hard. This may be the reason goal kicks produced the highest recorded speeds and forces overall.

Throw-in's yielded the slowest recorded speeds and least forceful impacts. Not only is the ball thrown overhead, a movement pattern which produces less force than kicking, but the ball is being thrown to a teammate who is sometimes as close to 5 yards away. It is a method of restarting the game and keeping possession of the ball on the restart as opposed to corner kicks or goal kicks where the objective is to score a goal or defend the goal.

Ball Speed

The average ball speed during this study was $39.5 \pm 17.5 \mathrm{mph}$. Studies have reported that while balls have been clocked at over $62 \mathrm{mph}$, the majority of balls that are headed are between $40-52 \mathrm{mph}^{15}$ Using that figure, this study found that of 42 headers performed, thirty-six percent $(n=15)$ fell within the range, fifty-two percent $(n=22)$ fell below the range and headers above the range accounted for the remaining twelve percent $(n=5)$. Of the trials that resulted in speeds below the range stated above, throw-ins accounted for sixty-eight percent $(n=15)$ as every throw-in was well below the average speed range. The trials in this study resulted in almost an even distribution of headers falling below or within the average speed range. The real-life ratio of throw-in's to other heading scenarios in practice and games is not known but it is important to note that a significant number of headers occur with ball speeds between 40-52 $\mathrm{mph}$ and sometimes greater. The repetitive use of the unprotected head to purposely make contact with a ball that has the potential to travel upwards of $60+$ mph is very concerning; especially when elite players report they have been heading since they were about 12 years old and the 
average number of headers reported by the subjects was approximately 12 times per game and practice. The speed of the ball was recorded after it was kicked and not right before impact. While the ball velocity was most likely lower when it made contact with the head, the act of the player heading the ball adds velocity. Therefore, as only average speed was recorded by the radar gun only during the initial kicking motion, additional studies should evaluate the entire process from kick to header impact by the other player, which may produce more realistic speeds of the ball.

Site of Impact

The pressure film was a small sample, 4in W x 10.6 in L. While some images produced very obvious visible outlines of the soccer ball, the film did not cover the entire head and so it was difficult to determine where on the head the ball struck. For the majority of the trials the areas of greatest pressure were centered in the film so it is safe to assume the site of impact was at the hairline, which is consistent with heading techniques. ${ }^{16}$ Impact Mechanics

Using the relationship of $\mathrm{f}=\mathrm{m}(\mathrm{a})$, where $\mathrm{f}$ is the force of the impact, $\mathrm{m}$ is the mass of the object and a is the acceleration of that object at any given time, one can determine the mechanics of the impact. This study used Size 5 soccer balls as those are the standard size used in collegiate soccer. Research conducted previously has found that a ball moving at a speed of $40 \mathrm{mph}$ will have an impact on an object for 10.23 milliseconds and produce anywhere from 191-205 lbf., ${ }^{45}$ Head impacts in sports such as football tend to produce higher $\mathrm{G}$ forces and impact duration. Peak accelerations of the head during the act of heading a soccer ball traveling at $39.3 \pm 1.8 \mathrm{mph}$ from 30 yards away were higher 
than those seen in football linemen and ice hockey players wearing similar accelerometers. ${ }^{2,11,15}$ Calculated injury threshold scores were well below those deemed to cause significant brain injury but were still higher than those seen in football and ice hockey players. ${ }^{2,11,15}$ Studies conducted with boxers have found that impacts can produce up to $1349 \mathrm{lbf}$ but the impact only occurs for 14-18 milliseconds. ${ }^{4,15}$ In this study, the duration of the impact was approximately 1-4 milliseconds with forces between 300 to $1000 \mathrm{lbf}$. As the average number of headers reported by the subjects was approximately 12 times per game and practice, this may be cause for concern long term. Duration of the impact is important to note when examining forces associated with impact. When there is high force with low impact duration there is a greater risk for injury. The injury threshold for concussive forces has been estimated at about $22 \mathrm{~N} / \mathrm{sec}^{4}$, 15

Individual Variations with Heading

The act of heading in soccer serves multiple purposes. A player can purposely use their head to make contact with the ball in order to score a goal, pass the ball, or clear it defensively. Using the head to purposely strike an object that can travel at speeds upwards of 40mph coupled with the fact that there is typically no protective equipment worn gives rise to some concerns. The act of properly heading the ball is intricate enough and it is rare that a player ever heads the ball in a stationary position during a game.

Important variables to take into account with regards to heading are rotational motions, head angulations, ball velocity, head acceleration rates, head to ball mass ratio, technical ability of the player and level of competition. Subject 3 produced the most 
variability with forces ranging from 300 to $1023 \mathrm{lbf}$ for all scenarios. Goal kicks produced variability with speeds ranging from 41 to 48 and the forces for the four kicks were different with duration of impact times for 2-3 milliseconds. For the throw-in's with Subject 3 there were 3 trials that were clocked at $29 \mathrm{mph}$ yet all three trials yielded a different force. (Figure D3.) This may be indicative of Subject 3 having a more aggressive heading technique where he was attacking the ball more than the other subjects. Lower impact time also supports this suggestion. Momentum and Restitution Coefficient

Examining the momentum with which a ball impacts the head is important as is the restitution coefficient. Both the player and the ball have a certain momentum dependent on the mass and velocity of each. While some of the trials demonstrated a large differential in the forces they produced, the momentums were similar. Subject 3's Goal Kick Trials 1 and 2 illustrate this as Trial 1 had a force of $540.46 \mathrm{lbf}$, and a momentum of $2.14 \mathrm{lb} / \mathrm{in}^{2}$ while Trial 2 was almost double the force at 1,033.09 lbf but the momentum was $2.20 \mathrm{lb} / \mathrm{in}^{2}$. Due to similar momentums, severities of the impacts are almost equal regardless of the difference in force. This is due to a higher force over a shorter period of time or lower force with a longer duration of impact. The duration of impact for Trial 1 was almost twice as long, lasting $3.99 \mathrm{~ms}$, as opposed to Trial 2 which was 2.13 The momentum seen with boxing is $5 \mathrm{x}$ 's the order of magnitude seen in soccer.

The restitution coefficient is representative of how much energy is dissipated by the ball when it makes contact with the head. The energy being dissipated is transferred 
to the head. Determining the coefficient of restitution demonstrates the ratio of incoming and outgoing velocities of a ball that strikes perpendicularly to the head.

Clinical Implications

Boxers, football players and ice hockey players have all demonstrated cognitive dysfunction, early onset dementia and chronic traumatic encephalopathy caused by repetitive blows to the head. ${ }^{8-11}$ While these impacts may not have produced acute symptoms, the accumulation has led to detrimental changes in the brain. Studies conducted previously have reported lower ball speeds and higher impact durations demonstrated in this study; both factors which influence potential risk. ${ }^{4,10,11,15}$ These results may not be as accurate a representation as to what occurs in a game due to all the un-controlled variables. As this study attempted to simulate a real-life game situation variability was evident.

Boxers who take hits of 1350 pounds of force over 14 milliseconds are showing physical changes in the brain as well as cognitive dysfunction. ${ }^{15}$ Some corner and goal kick trials in this study resulted in forces almost close to that. Thus, the argument can be made that soccer players are definitely at risk for long-term sequlelae from repetitive heading. Despite the forces, the momentum with which an impact occurs is lower than those seen in football and boxing.

Additional studies should be conducted long term to note if forces and momentum are consistent over time with repetitive heading that could lead to long-term sequlelae as more research is beginning to emerge on heading in soccer as well as longterm cognitive deficits being seen in former soccer players. Head acceleration is the most commonly examined to determine concussion risk but it is correlated with cranial fracture 
and not concussion. Angular acceleration and brain tissue strain are more important factors to determine concussion risk caused by shifting of neural tissue inside the skull.

Soccer is the only sport that utilizes an unprotected head to purposely make contact with an object that can travel up to $60 \mathrm{mph}$. As children are starting to play at a younger age and athletes are becoming bigger, faster and stronger the concern for longterm damage from repetitive heading is growing. To thoroughly comprehend the potential risk more research is needed to determine a sub-concussive injury threshold, examine the cumulative effects of heading and determine what is happening to the brain during heading.

\section{Limitations}

With a descriptive study being conducted limitations may be apparent, which should be addressed in future studies. Biomechanical factors such as head and neck strength, tensile loading of the neck muscles and head and neck positioning were not examined. Acceleration/deceleration of the head was not examined either with accelerometers. The majority of the literature regarding concussive forces with impacts in sports focused on these forces, as well as rotational forces, because they are prime mechanisms for head injury. By examining the force of the impact, as this study did, only one component was analyzed. Due to the lack of literature regarding forces sustained with impacts it was difficult to compare the results yielded from this study. The small sample size used does not allow for a generalization to a larger population and because only males were used it also prevents generalizing to female collegiate soccer players. 
During the act of heading the ball impacts the player's head for a very short amount of time (on the order of milliseconds). Using pressure film may provide a more detailed profile of an impacting load. However, only peak pressures are seen at each point. Though the sheets come with standard calibration curves, the accuracy is limited to $\pm 5 \%$ due to variations in the manufacturing process of the microcapsules. Even with the calibration curves, the measurements can only be said to be "relative" rather than the accurate measurements of a tuned and calibrated electronic sensor circuit.

The analysis process may have skewed results, making the findings difficult to compare to data reported in the literature. The total area scanned and analyzed was much greater than the true total area of the pressure film. The total area scanned was 204 sq. in., which was the entire surface of the scanning equipment. Each piece of pressure film was 46.64 sq. in. Instead of cropping the scanned image to just include the pressure film once it was uploaded to the analysis software, the entire scanned image, which was 204 sq. in., was analyzed. This may have altered the calculations for PSI across the contact area, which in turn would have skewed the force results.

The pressure film may not have accurately captured the force profile of each trial because it may have been too sensitive. Evidence of this is displayed in Table D1-3 where the minimum and maximum PSI recorded for every trial covers the full spectrum of the film range. In addition, in some heading scenarios the contact area may not have been centered on the pressure film. A portion of the impact may have occurred off the pressure film depending on where the ball made contact. In trials that yielded a low contact area but higher speed, the force result may be lower due to part of the impact occurring off the paper and not being recorded. 


\section{CONCLUSION}

The aim of this study was to quantify forces occurring during the act of soccer. Goal kicks proved to impact the head with the most force, followed by corner kicks and throw-in's. Forty-two trials were conducted in which 3 subjects each headed a ball 5 times at 3 different heading stations, each meant to simulate a common heading scenario that occurs in practices and games. The speeds and forces vary based on subject as well as scenario but demonstrate that ball speeds are capable of travelling as low as $26 \mathrm{mph}$ and as high as $57 \mathrm{mph}$. Forces upon impact also varied from about 300 lbf to over 1,000 lbf. In order to better understand what implications this holds for soccer players one must also be able to analyze the duration of impact and acceleration/deceleration of the head. 


\section{REFERENCES}

1. McRory P, Meeuwisse W, Johnston K et al. Consensus statement on concussion in sport: the $3^{\text {rd }}$ international conference on concussion in sport held in Zurich, November 2008. Br J Sports Med. 2009; 43:i76-i84.

2. Park MS, Levy ML. Biomechanical aspects of sports related head injuries. Neurol Clin. 2008; 26:33-43.

3. Meany DF, Smith DH. Biomechanics of concussion. Clin Sports Med. 2011; 30:19-31.

4. Kirkendall DT, Jordan SE, Garrett WE. Heading and head injuries in soccer. Sports Med. 2001; 31(5):369-86.

5. Boden BP, Kirkendall DT, Garret WE Jr. Concussion incidence in elite college soccer players. Am J Sports Med. 1996; 26:238-41.

6. Delaney SJ, Puni V, Rouah F. Mechanics of injury for concussion in university football, ice hockey and soccer. Clin J Sports Med. 2006; 16(2);162-5.

7. Withnall C, Shewchenko N, Gittens R et al. Biomechanical investigation of head impacts in football. Br J Sports Med. 2005; 39:i49-i57.

8. Barnes BC, Cooper L, Kirkendall DT et al. Concussion history in elite male and female soccer players. Am J Sports Med. 1998; 26(3):433-38.

9. Landry GL. Central nervous system trauma management of concussion in athletes. Pediatr Clin N Am. 2002; 49:723-41.

10. Delaney SJ, Lacroix VJ, Leclerc S et al. Concussions among university football and soccer players. Clin J Sports Med. 2002; 12(6):331-8.

11. Naunheim R, Standeven J, Richter C et al. Comparison of impact data in hockey, football and soccer. J Trauma. 2000; 48(5):938-41.

12. Schmitt DM, Hertel J, Evans TA et al. Effect of an acute bout of soccer heading on postural control and self reported concussion symptoms. Int J Sports Med. 2004; 25:326-31.

13. Webbe FM, Ochs SR. Recencey and frequency of soccer heading interaction to decrease neurocognitive performance. Appl Neuropsychol. 2003; 10(1):31-41.

14. Posey RP. Soccer headgear effects in impact profiles during a heading scenario. etd.lib.clemson.edu. 2006. 
15. Kirkendall DT, Garrett WE. Heading in soccer: integral skill or grounds for cognitive dysfunction? J Athl Train. 2001; 36(3):328-33.

16. Shewchenko N, Withnall C, Keown M et al. Heading injuries in football. Part 1: development of biomechanical methods to investigate head response. Br J Sports Med. 2005;39:i10-i25. 
APPENDICES 


\section{APPENDIX A}

\section{Research Question}

\section{THE PROBLEM}

With soccer being the most popular sport worldwide it comes as no surprise that there are more than 200 million soccer players around the globe. ${ }^{11}$ In a sport with this many individuals participating there is a significantly high chance for serious injury to occur. While soccer is mainly a lower extremity sport it is unique in the aspect that the head is used to purposefully maneuver the ball..$^{2,4,8,11}$ What makes this sport even more unique, and possibly more risky, is that the head is completely unprotected. In other sports where there is potential for head impact due to the nature of the sport a helmet is typically worn, such as football, lacrosse and hockey, to protect the head. Soccer does not require head protection and until recently, there was no equipment on the market to provide protection. Because individuals intentionally challenge each other to gain control of the ball while it is in the air during the act of heading there is an added risk of injuries occurring from head-to-head contact as well as head-to-ball. ${ }^{4}$ Other ways in which a player can sustain a head injury while playing soccer are head to extremity, head to goalpost and head to ground. ${ }^{4}$

Studies examining the mechanism of heading among professional soccer players revealed that heading the ball may occur over 2,000 times in a career. ${ }^{11}$ Peak accelerations of the head during the act of heading are significantly higher than those in both football and ice hockey $y^{2,11}$ and with the estimated number of times a soccer player may head the ball throughout the course of their career certainly warrants asking if there is a potential for long-term sequelae. 
The primary focus of the majority of studies being conducted recently regarding long term effects of concussions or sub-concussive impacts has been American football. Studies have also been conducted regarding boxing and the long term consequences associated with numerous blows to the head. It should be noted that the long-term physical and cognitive changes that may occur in the brain in both football players and boxers are starting to be attributed to the repetitive sub-concussive impacts that these athletes sustain day in and day out both when practicing and playing. This means that while there are impacts in both sports that may lead to a clinical diagnosis of concussion or loss of consciousness it is the hits that do not produce those symptoms that may be most detrimental in the long run. If that is the case, then one can make the argument that soccer players may be experiencing the same types of sub-concussive impacts when heading the ball. ${ }^{11}$

While researching the existing literature for this topic it became apparent that there is lack evidence regarding not only long term effects of repetitive sub-concussive impacts in soccer players but in the frequency of concussions among soccer players in general. Studies that have been performed differ slightly in their reported numbers but it is estimated that head injuries account for approximately $4-22 \% .^{4,8}$ It is important to note that these numbers are not limited to mild traumatic brain injuries. These reports include all head injuries including nasal fractures and facial lacerations., ${ }^{4,8}$

In addition to looking at concussion and mTBI rates and frequency it is important to examine the forces that could potentially serve as the mechanism for these injuries. By quantifying the forces seen with heading and comparing the numbers to those found in the literature we may be able to determine if headers pose a risk for long-term damage. 


\section{Research Questions}

1. Which heading scenario will have the greatest force transfer from ball to head corner kick, goal kick or a throw-in?

2. Is there intra and inter player consistency seen with the heading forces?

3. Does the distance the ball is travelling affect the forces associated with it?

Experimental Hypothesis

1. Corner kicks will have the greatest forces.

2. There will be intra and inter player consistency with heading forces.

3. Distance that the ball is travelling will have an effect on the forces recorded with longer distances producing less force.

\section{Assumptions}

1. The participant will head the ball every time.

2. The pressure film will produce usable data that can be analyzed.

\section{Delimitations}

1. Due to use of all male subjects, the results may not be able to be generalized to females.

2. Variability of the velocity of the ball during kicks.

3. Variability of heading styles and head contact area.

\section{Limitations}

1. The biomechanics of heading are not being examined.

2. The study will be specific to a small sample in a D1 collegiate soccer program in the Mid-Atlantic US.

3. This study will not relate to all athletes that head the ball during a game as only three athletes will be used. 
Operational Definitions

1. Average pressure - The figure used to represent the difference or middle value between the maximum and minimum pressure.

2. Ball velocity - Speed at which a soccer ball is traveling ${ }^{6,7}$

3. Biomechanical forces - internal and/or external forces acting on the body and the effects produced by those forces ${ }^{2,3,9,12}$

4. Concussion - Complex pathophysiological process affecting the brain, induced by traumatic biomechanical forces ${ }^{1}$

5. Corner kick - Method of restarting a soccer game, commonly seen as a potential goal scoring opportunity. Kick is taken from the corner of the field after the ball goes out of bounds.

6. Force - mass $\mathrm{x}$ acceleration ${ }^{15}$

7. Goal kick - Method of restarting a soccer game. Kick is usually taken by the goalie from anywhere inside the defending goal area.

8. Heading - Intentional use of the head to direct a ball during the game of soccer Can be used to pass the ball, clear the ball or score a goal. ${ }^{15}$

9. Minimum pressure - The lowest pressure recorded on the film.

10. Maximum pressure - The highest pressure recorded on the film.

11. Pressure sensitive film - film used to measure peak contact forces between two surfaces $^{14}$

12. Sub-concussive impacts - impacts that do not produce immediate, transient signs or symptoms of a concussion but have been shown to do cumulative damage to the brain $1,4,10,11,13$

13. Throw-in - Method of restarting a soccer game. Ball is thrown inbounds in an overhead fashion after it has gone out of bounds via a sideline.

Significance of the Study

The number of individuals that play soccer around the world is higher than any other sport. While not all individuals who play will have a "career" that is comparable in 
number of years played to that of a professional or elite player it is still important to recognize the impact that studies and research on concussions and sub-concussive impacts in soccer may have on the sport and the athletes who play. Long term sequelae includes but is not limited to altered behavior, memory loss, degeneration of fine motor skills, constant headaches and even death.

This study will examine forces associated with heading during three different types of kicks in soccer. By quantifying those forces we may be able to show if they are similar to the forces reported in football and ice hockey players during impacts.

Research is essential to making the game safer for those who choose to play. These safety measures may come in the form of rule changes, altering practices or limiting headers at practices, development of equipment or modification to existing protective equipment to make it more effective. Educating players, coaches, parents and medical personnel about the potential risks associated with heading the ball, even when there are no concussive symptoms produced, has the potential to safe guard against the long term effects associated with repetitive sub-concussive impacts but in order to do so the amount of research and literature available must be more substantial.

There are various ways to distribute this information to those it would be most applicable to once it is available. Educating medical personnel should be the first step as they have the greatest means and resources to access the most up to date information. This information can be delivered in several ways; workshops, presentations, conventions and publications will be the most effective way to reach such a large population. Coaches, parents and players can be educated by team physicians and athletic trainers as 
well as read publications made available to the general public who may not have the extensive medical knowledge that doctors or athletic trainers possess. 


\section{APPENDIX B}

\section{LITERATURE REVIEW}

While concussions are a popular topic in the sports community, few people are aware of what defines a concussion. One of the reasons for this is that no standardized definition exists. ${ }^{9}$ The most recent definition was drafted and agreed upon by a panel of experts at the $3^{\text {rd }}$ International Conference on Concussion in Sport held in Zurich in 2009. According to the consensus statement a concussion can be defined as a "complex pathophysiological process affecting the brain, induced by traumatic biomechanical forces." It is also important to clarify that a concussion differs from a mild traumatic brain injury (mTBI) and the two should not be used interchangeably. ${ }^{1,9}$ Using the proper terminology is important as the two terms can be representative of varying degrees of severity and imply different recovery timelines and outcomes. Referring to an injury sustained by an athlete as an mTBI instead of a concussion may yield different responses to questions as well. This literature review will examine the etiology, pathophysiology and epidemiology of concussions as well as heading in soccer, the biomechanics of heading and the short-term effects of heading on cognitive function.

\section{Etiology}

While the focus of this study is forces incurred during heading it is important to examine how most concussions are sustained in soccer. Boden et al. ${ }^{5}$ reported that the most common mechanism of injury was head to head contact. A study conducted by Delaney et al. ${ }^{10}$ supported this finding after recording the number of concussions sustained by collegiate soccer players over a 3 -year period. Of the 18 concussions that were documented, 6 of were the result of head to head contact. ${ }^{10}$ Conversely 
Shewchenko et al. ${ }^{16}$ reported that head to body accounted for $41 \%$ of head impacts during heading followed by head to head at $32 \%$.

Head to body contact is frequently a cause of concussion. Boden et al. ${ }^{5}$ reported that of 29 concussions among collegiate soccer players over a 2 year period, $20 \%$ were the result of head to body contact. Most commonly the elbow is the body part that is imparting the blow to the head but in some cases the foot and knee were used. ${ }^{6,7,16}$

Head to ball contact is found to be the most infrequent cause of concussions during the act of heading in the literature. ${ }^{4,7,10}$ Typically, head to ball incidents that result in concussions are due to accidental contact and are not the result of intentional heading. In one study that examined mechanisms for almost 30 concussions, head to ball contact was never a cause. ${ }^{10}$ An important question to ask is how do these impacts lead to a concussion? For that, one must consider how a concussion occurs.

Biomechanical forces acting on the head are the cause of concussions. ${ }^{2}$ Concussions occurring from a player's head striking a stationary object (e.g. ground, goalpost, etc.) or an accidental head to ball collision in which the head is stationary and the ball is moving arise from acceleration-deceleration mechanisms. ${ }^{2,3}$ Rotationalacceleration injuries are also possible, especially due to the head being fixed along the long axis of the spine. ${ }^{2,3}$

Acceleration-deceleration can lead to tensile, linear and compressive forces on the brain. ${ }^{2}$ When the head is struck with an object or strikes an object the skull is first to move followed by the brain. This delay allows enough time for the brain to make contact with the interior surface of the skull which, in stark contrast to the smooth external surface, has bony irregularities and protrusions. ${ }^{4}$ The skull is also the first thing to stop 
while the brain continues and again strikes the inside of the skull. This injury is known as a coup-contrecoup head injury. Rotational mechanisms typically produce shear forces and are more likely to lead to a concussion. ${ }^{3}$ The reason for this is because brain tissue is more sensitive to deformation when shear forces are present. ${ }^{3}$ Shear forces can cause axonal tearing as well as tearing of vascular structures. ${ }^{4}$

Pathophysiology

When an insult occurs to the brain there are a series of events that take place that are typically referred to as the neurometabolic cascade. These changes occur on the physiologic, metabolic and ionic levels. ${ }^{17,18}$ Following an injury there is an unrestrained release of neurotransmitters and fluctuations of ions that occur simultaneously. ${ }^{18}$ Excitatory transmitters such as glutamate bind to receptors like N-methyl-D-aspartate (NMDA). ${ }^{17,18}$ NMDA's serves synapse function in that it controls the strength of the synapse based on how often it is used; much like the SAID principle but on a cellular level. ${ }^{17}$ The SAID principle states that the body will respond and adapt to the specific demands placed on it. NMDA also plays a role in memory. When this binding occurs it causes additional depolarization coupled with an outflow of sodium $\left(\mathrm{Na}^{+)}\right.$and inflow of potassium $\left(\mathrm{K}^{+}\right)$. Acute and sub-acute changes occur in regards to the physiology of the cell due to these ionic changes.

This disruption of cell physiology causes an imbalance in the neuronal membrane potential. The $\mathrm{Na}^{+} \mathrm{K}^{+}$pump begins to work overtime in an effort to restore this balance and maintain neuronal homeostasis. Due to this extra effort there is in an increased need for adenosine triphosphate (ATP). ${ }^{17}$ ATP is crucial to cell function. This increased demand for ATP leads to an increase in glucose metabolism. Unfortunately at the same 
time that there is a hypermetabolism of glucose there is also a decrease in cerebral blood flow $(\mathrm{CBF}) .{ }^{17,18} \mathrm{~A}$ decreased $\mathrm{CBF}$ means that the demands for glucose and ATP are not being met and this causes somewhat of an energy emergency within the cells. ${ }^{17,18}$

Following the period of accelerated glucose metabolism the brain experiences the exact opposite - metabolic depression. During this depressed period there is still an influx of calcium. This uninhibited build up of calcium within the axon can cause damage to the neurofilaments and microtubules, both of which are essential to neural connectivity. ${ }^{17,18}$ The end result can be cell death. In addition to axonal damage, increased amounts of calcium can mar mitochondrial oxidative metabolism. ${ }^{18}$ This process is important because it allows for production of ATP when the mitochondria are functioning properly. Impaired mitochondrial function leads to a reduction in ATP.

Glycolysis is triggered when there is in an inadequate amount of ATP being produced and sudden increase in energy requirements due to an overworked $\mathrm{Na}^{+} \mathrm{K}^{+}$ pump. When the glycolysis process is accelerated, lactate is produced. At the same time that lactate is being produced there is a decrease in the metabolism of lactate which leads to a build up. Lactate build up can lead to complications such as acidosis, compromised blood brain barrier permeability and cerebral edema. ${ }^{17,18}$

Other pathophysiologic concerns are decreased levels of magnesium within the cell, which has been suggested as one of the causes for neurologic deficits and impaired motor performance. ${ }^{17,18}$ Long-term memory and cognitive function may also be impaired due to compromised strength of synapses. As mentioned earlier the potentiation (increased strength of synapses) is dependent upon NMDA. NMDA systems may be altered following a concussion. 


\section{Epidemiology}

Concussions account for a small percentage of injuries relative to the total number of injuries and types of injuries sustained in soccer. ${ }^{3,8,9}$ The rate of concussion in soccer tends to change depending on the age group being examined. Youth soccer has minimal reports pertaining to frequency of concussion. One argument that can be made is that younger players do not head the ball nearly as often as older players. The majority of concussions occur during the act of heading so it would make sense that there are very few concussions occurring among youth players.

Studies have shown that concussions can account for $3.9 \%$ of injuries among boys soccer players, ages $15-18$. That percentage increases to $4.3 \%$ among girls in the same age group. ${ }^{4,9,19}$ It has been estimated that a boys' team will sustain 0.22 concussions per season while a girls' team will sustain 0.26 concussions. ${ }^{9}$ According to an injury survey conducted by the National Athletic Trainers' Association from 1995-1997, concussion rates among high school boys and girls soccer were 0.18/1,000 athletic exposures and $.23 / 1,000$ athletic exposures, respectively. ${ }^{9}$

These numbers increase with age and level. The National Collegiate Athletic Association reported that concussions were 7\% of all game injuries sustained in men's soccer and $11 \%$ in women's soccer. ${ }^{9}$ This drastic increase can be attributed to a multitude of variables such as speed, strength, competition level and athleticism.

Gordon et al. ${ }^{20}$ reviewed the results of the Canadian National Health Survey from 1996-1997 and found that of the 81,634 (99.8\% response rate) participants, 89 reported that a concussion was their most serious injury in the previous year. This number was representative of 110 concussions per 100,000 people. ${ }^{20}$ This also does not account for 
those individuals who may have sustained a concussion throughout the year but also sustained other injuries that they considered more serious. Of those 89 reported concussions, more than $54 \%$ were sport-related and more than $85 \%$ were related to sport in 16-34 year old population. ${ }^{20}$ They also found that males were more likely to sustain and report a concussion.

A study conducted by Delaney et al. ${ }^{10}$ examined the incidence of concussion among Canadian college football and soccer athletes over a one-year period. Of the 240 soccer players they surveyed, $67.2 \%$ reported experiencing symptoms of a concussion but only $19.8 \%$ of concussed players were aware that they actually had a concussion. Of those concussed players, $87.1 \%$ had experienced more than one concussion in the year. Goalies seemed to be most susceptible to concussions, which could be attributed to the demands of their position. ${ }^{4,10}$ Female soccer players reported having more concussions than males. ${ }^{10}$

When Barnes et al. ${ }^{8}$ interviewed 72 male and 72 female soccer players at the 1993 Olympic Sports Festival. They found that there were 74 concussions among 39 male players and 48 of these 74 concussions resulted from collisions with another player. Their finding that men were more likely to sustain a concussion than women is interesting as most of the literature and data suggested that women are more susceptible. According to their survey men were more than two times as likely to sustain a concussion as women. Twenty-four men and three women reported having sustained more than one concussion over the course of their careers. ${ }^{8}$ Heading in Soccer 
The act of heading in soccer serves multiple purposes. A player can purposely use their head to make contact with the ball in order to score a goal, pass the ball, or clear it defensively. Using the head to purposely strike an object that can travel at speeds upwards of 40mph coupled with the fact that there is typically no protective equipment worn gives rise to some concerns. The act of properly heading the ball is intricate enough and it is rare that a player ever heads the ball in a stationary position during a game.

Biomechanics

Proper technique is required to head the ball properly depending on what that player is trying to do, whether it be shoot, pass or clear the ball. General heading mechanics consist of three phases: pre-impact or preparation, ball contact and follow through. ${ }^{16}$

During the preparation phase the player should have their knees slightly bent with their feet apart. Their shoulders should be squared to the ball and trunk extension should be present. ${ }^{16}$ This body positioning prepares the athlete to meet the ball to make contact, not just allow the ball to strike them. The actual contact phase requires the athlete to perform trunk flexion. The head and shoulders should stay in line with the trunk and the entire upper body should move as one unit. It is important that neck muscle activation occur as this can help with head - neck coupling and may help to counterbalance the force being imparted by the ball. ${ }^{16,21}$ The point of impact that most literature and coaching manuals suggested for the ball is at the hairline as opposed to the top of the head. The thickness of the frontal bone may help to attenuate the force of the ball upon impact. ${ }^{16,22}$ Finally; the follow-through phase consisted of the upper body continuing to 
move in the direction of the intended target. Eventual deceleration allowed the athlete to regain balance and control. ${ }^{16}$

Interestingly, Shewchenko et al. ${ }^{16,21}$ found that pre-loading of the neck muscles prior to ball contact actually creates an increase in axial and shear loads in the cervical spine. $^{1,2}$

Other important variables to take into account with regards to heading are rotational motions, head angulations, ball velocity, head acceleration rates, head to ball mass ratio, technical ability of the player and level of competition. ${ }^{22}$ Short-term effects of heading

Numerous studies have shown that head to ball contact is rarely the cause for concussive symptoms. This does not mean that there are no effects on the brain following repetitive heading in a game or heading drills in practice. Schmitt et al. ${ }^{12}$ compared two, randomly selected groups of collegiate level soccer players who were split into kicking and heading groups to determine if acute repetitive heading had any adverse effects on self-reported concussion symptoms. ${ }^{12}$ While there were no significant differences between the two groups at baseline and 24 hours post heading, immediately following the heading exercise the heading group reported significantly more symptoms than the kicking group. ${ }^{12}$ Symptoms that were most frequently reported were headache, dizziness and feeling "slowed down". ${ }^{12}$ While it is unlikely that most players will experience the amount of heading (18 consecutive headers) performed by participants in the study in a game setting, it is possible for them to reach a number close to that in practice depending on the position they play and if they are considered a "header". 4,12 
Weebe and Ochs support ${ }^{13}$ the suggestion that there are short-term effects with the results of their 2003 study. Sixty-four high level soccer players, ages 16-34, were asked to perform a series of neuropsychologic tests that included the California Verbal Learning Test (CLVT) and Trailmaking test and Shipley Scales. The findings revealed that players with the highest self-reported estimates of heading incidences coupled with experiencing heading in the previous 7 days had scores that were significantly lower on the three previously mentioned tests than other players in the study. ${ }^{13}$

While follow-up testing was not done in Weebe and Orchs ${ }^{13}$ study as was done with $\mathrm{Schmitt}^{12}$, one cannot dispute that there is a manifestation of physical symptoms and cognitive impairments following acute bouts of repetitive heading. These findings and considerations raise the issue of accumulation of these effects over a period of time. Potential for long-term effects

The effects of repetitive concussions as well as sub-concussive impacts in football players, ice hockey players and boxers are well documented. Soccer players have been shown to have a concussion incidence rate that is almost as high as football players. ${ }^{12}$ The long term effects associated with repetitive concussions has not been documented nearly as well as in other high-impact sports. Recent studies support the need for further testing to examine possible long-term behavioral and cognitive changes.

Tysvaer et al. ${ }^{23}$ examined electroencephalographic (EEG) data obtained from active and retired soccer players who averaged 128 games. The players were between the ages of 15 and 35 and were matched with a control group of the same age that was from a non-athletic population. ${ }^{23}$ Of the retired players, $70 \%$ had abnormal neurologic results while $35 \%$ of both retired and active players had abnormal EEG data compared to $13 \%$ 
within the control group. ${ }^{12,23}$ One-third of the retired players also scored low enough on neuropsychological testing to suggest organic brain damage. ${ }^{12}$ Reported neurologic abnormalities included nystagmus, impaired coordination and reflex interruptions.

Soccer players have also shown deficits in memory, planning and visualproprioceptive processing. When compared to swimming and track athletes they have scored significantly lower in those testing areas and there has been a direct correlation to previous head injury. ${ }^{24}$ There have also been reports of structural changes in retired players that were considered "headers". Significantly higher rates of cortical atrophy were found in headers versus non-headers. Ventricle widening was also present in $18 \%$ of players with cortical atrophy and $27 \%$ who has cerebral atrophy. ${ }^{12,23}$

While the literature on long-term effects caused by repetitive impacts to the head in soccer is not nearly as abundant as that seen in other sports such as football and ice hockey, the findings from pilot studies certainly warrant the need to examine the risks associated with repetitive heading in soccer and the potential for long term damage.

\section{SUMMARY}

While no standard definition exists for a concussion it is important to recognize that concussions and mild traumatic brain injuries (mTBI) differ in more than one way. The two different terms refer to varying degrees of severity, recovery times and outcomes. Most concussions in soccer occur from head to head contact with another player while both are attempting to head the ball. It is rare that an athlete sustains a concussion during heading of the ball but it is possible.

The head striking another object can produce acceleration-deceleration forces or rotational forces. This can place tensile, compressive, linear and/or shear forces on the 
brain, which could bruise or tear structures in the brain. When the brain is injured a chain of events is set off known as the neurometabolic cascade. Chemical, physiologic and ionic changes take place within the brain. These changes can affect synapses that are important to memory and cognitive function.

Relative to all injuries seen in soccer, concussions are responsible for a small percentage; approximately $7-11 \%$ for men and women's teams, respectively. These numbers vary with age groups, with younger players having lower incidences reported. This is attributed to less heading at younger levels.

Due to the nature of heading, it is no surprise that there is an increased risk for head injury. The player utilizes their head intentionally, regardless of lack of protection, to direct the ball. Sometimes this technique is employed to pass the ball, defend a goal or in an attempt to score a goal. Proper technique is required to head effectively. Ideally, contact is made at the top of the forehead, just along the hairline. The shoulders and head should stay in line with the trunk as trunk flexion takes place during contact. Neck muscle activation is important to assist with head and neck coupling. This is also thought to help with counterbalancing the force imparted by the ball.

While concussions make up a small percentage of all injuries incurred in soccer, reported incidences reveal that there are almost as many concussions reported in soccer as there are in football. Long-term consequences have long been documented in other high-impact sports but the literature and research is not nearly as extensive on soccer players. Studies that have been conducted have revealed that retired soccer players showed memory deficits and cognitive impairment. Structural changes in the brain have also been noted. The findings from current studies warrant the need for more research to 
determine if soccer players are at risk for long-term consequences from sub-concussive impacts due to repetitive heading. 


\section{APPENDIX C}

\section{ADDITIONAL METHODS}

Table C1. Informed Consent

\section{Study Title:}

Examining the Forces Associated with Heading in Collegiate Soccer Athletes

\section{Co-Investigator(s):}

Tenore, Elizabeth

\section{Sponsor:}

N/A

\section{Contact Persons:}

In the event that you experience any side effects or injury related to this research, you should contact Elizabeth Tenore, ATC at (551)206-9135. If you should have any questions, concerns, or complaints about this research, you can contact Dr. Sandrey, the principle investigator at (304)293-0870. In addition, if you would like to discuss problems, concerns, have suggestions related to the research, or would like to offer input about the research, contact the Office of Research Integrity and Compliance at (304)2937073.

For information regarding your rights as a research subject, you may contact the Office of Research Compliance at (304)293-7073.

\section{Introduction:}

You have been asked to participate in this study, which has been explained to you by Elizabeth Tenore, BS, ATC. This study is being conducted by the Principle Investigator, Michelle A. Sandrey, PhD, ATC and the Co-Investigator, Elizabeth Tenore, BS, ATC, in the College of Physical Activity and Sport Sciences at West Virginia University. This research is being conducted to fulfill the requirements for a thesis in Athletic Training in the College of Physical Activity and Sport Sciences at West Virginia University under the supervision of Michelle A. Sandrey, PhD., ATC.

\section{Purposes of the Study}

The purpose of this study is to quantify and examine the foces that occure during different heading scenarios in soccer. WVU expects to enroll approximately 4 subjects, for a total of 4 subjects. This study will be conducted at the Men's Soccer Practice Facility, Jerry West Blvd., Morgantown, WV, 26505.

\section{Description of Procedures}

Orientation procedures: The purpose of this study will be explained to you prior to you being selected as a participant. You will be given an informed consent form/HIPPA form explaining you rights as a research subject. You will also be asked to complete a medical 
history questionnaire for inclusion/exclusion criteria. If you are one of the eligible subjects, you will be contacted by the principle researcher for participation in the study. Testing will take place during a scheduled testing session. You will be asked for your full cooperation and to put forth maximal effort. Your involvement in this will initially take approximately 2-3 hours for the testing session. This will be the only involvement and testing sessions required of you. The end of the testing session will conclude your participation in this study.

Interventions

Subjects will be asked to complete 5 headers at each of the 3 heading stations. These stations are goal kick, corner kick and throw-in. Testing will be administered and supervised by the co-investigator at the Men's Soccer Practice Facility. Prior to testing, the tests will be explained to your satisfaction. Heading subjects will be outfitted with pressure sensitive film on your head. This will allow the forces occurring with heading to be recorded for further analysis. Kicking subjects will not be outfitted with pressure sensitive film.

Heading subjects: The goal kick will require you to stand at the mid-field line and head the ball that is kicked from the goal line by the goalie. The corner kick will require you to stand in front of the net and head the ball that is crossed from the corner. The throw-in will require you to stand approximately 15 yards away from the thrower, on a diagonal and facing the direction you are receiving the ball from. Each subject will perform 5 repetitions per station for a total of 15 headers through the entire testing session. The pressure film will be changed following each successful header.

Kicking subjects: Goal kicks will require you to kick the ball to the header at the midfield from the goal line. Corner kicks will require you to cross the ball in front of the goal from the corner. Throw-ins will require you to throw the ball to the header from the sideline using proper overhead throw-in technique.

\section{Risks and Discomforts}

There are no known or expected risks from participating in this study. However, stretching and warm up will be performed prior to and after testing. Should any injury occur, you understand that Elizabeth Tenore, ATC, will provide first aid and make any necessary referral at your expense.

\section{Alternatives}

You understand that you do not have to participate in this study. No negative actions will be taken against you if you chose not to participate.

\section{Benefits}

You understand that this study is not expected to be of direct benefit to you, but the knowledge gained may be of benefit to others. 


\section{Financial Considerations}

You will receive no financial remuneration for completing this study.

\section{Confidentiality}

We know that information about you and your health is private. We are dedicated to protecting privacy of that information. Because of this promise, we must get your written authorization (permission) before we may use or disclose your protected health information or share it with others for research purposes. This form gives that permission. It also helps us make sure you are correctly told how this information will be used or disclosed. Please read the information below carefully before signing this form. Please ask any questions you may have about this form or its uses. You can decide to sign or not sign this authorization form. However, if you chose not to sign this authorization for, you will not be able to take part in the research study. Whatever choice you make about this research study, it will not have an effect on your access to medical care.

USE AND DISCLOSURE COVERED BY THIS AUTHORIZATION. DO NOT SIGN A BLANK FORM. You or your authorized representative should thoroughly read the information below before signing this form. This form will authorize the following person(s), class(es) of person(s), and/or organization(s) to disclose, use, and receive the information: WVU, Michelle A. Sandrey, Ph.D., ATC, Elizabeth Tenore, ATC. The research site(s) carrying out this study include WVU. It also includes each site's research staff and medical staff. Health care providers who provide services to you as part of this research study include Elizabeth Tenore, ATC. If, during the course of the research, the institution listed above merges with, or is purchased by, another company or institution, this authorization to use or disclose protected health information in the research will extend to the successor company or institution. A self-report medical history that includes information about past medical history of any lower or upper limb, head or neck injuries is included in this study.

SPECIFIC UNDERSTANDINGS. By signing this research authorization form, you give permission for the use and/or disclosure of your protected health information described above. The purpose for the uses and disclosures you are authorizing is to carry out the research study explained to you during the informed consent process. It is also to ensure that the information relating to the research is available to all parties who may need it for research purposes. Your protected health information may be used as necessary for research-related treatment. This information may be redisclosed or used for other purposes if a recipient described in this form is not required by law to protect the privacy of the information. You have a right to refuse to sign the authorization. Your health care outside the study, the payment for your health care, and your health care benefits will NOT be affected if you do not sign the form. However, you will NOT be able to take part in the research study described in this authorization if you do not sign this form. If you sign this authorization, you will have the right to cancel it at any time, except to the extent that WVU has already taken actions based on your authorization or needs the information to complete analysis and reports of data for this research study. You may cancel this authorization at any time by writing to the principle investigator, Michelle A. 
Sandrey, Ph. D, at: West Virginia University, PO Box 6116, Morgantown, WV 26506. If you cancel this authorization, any information that was collected already for this study cannot be withdrawn. Once information is disclosed, according to this authorization the recipient may redisclose it and then the information may no longer be protected by federal privacy regulations. You will NOT be allowed to see or copy the information described on this form as long as the research is in progress, but you have a right to see and copy this information upon completion of the research in accordance with hospital policies. You have a right to receive a copy of this form after you have signed it. This authorization will not expire unless you cancel it. Expiration Date: NONE

In any publications that result from this research, neither your name nor any information from which you might be identified will be published without your consent.

\title{
THIS SUBJECT OR HIS/HER AUTHORIZED REPRESENTATIVE MUST BE PROVIDED WITH A COPY OF THIS FORM AFTE R IT HAS BEEN SIGNED. By writing to the Principle Investigator:
}

\author{
Michelle A. Sandrey, Ph.D. \\ West Virginia University \\ PO Box 6116 \\ Morgantown, WV 26506
}

You have a right to see and make copies of your medical records. You will not be able to see or copy your records related to the study until the sponsor has completed all work related to the study. At that time you may as to the see the study doctor's files related to your participation in the study and have the study doctor correct any information about you that is wrong.

\section{SIGNATURE}

I have read this section and all of my questions have been answered. By signing below, I acknowledge that I have read and accept all of the above.

Signature of Subject or Authorized Representative

Date

Print Name of Subject or Authorized Representative

\section{Voluntary Participation}

Participation in this study is voluntary. You are free to withdraw your consent to participate in this study at any time. Refusal to participate or withdrawal will not affect your future care, or your employee status at West Virginia University or your position on the soccer team, and will involve no penalty to you. In the event new information becomes available that may affect your willingness to participate in this study, this information will be given to you so that you can make an informed decision about 
whether or not to continue your participation. You have been given the opportunity to ask questions about the research, and you have received answers concerning the areas you did not understand.

Upon signing this form, you will receive a copy.

I willingly consent to participate in this research.

Signature of Subject

Printed Name

Date

Time

Subjects Legal Representative

The participant has had the opportunity to have questions addressed. The participant willingly agrees to be in the study.

Signature of Investigator or

Printed Name

Date

Time

Co-Investigator 
Table C2. Demographic and Injury Questionnaire

\section{DEMOGRAPHIC INFORMATION}

Name:

Age:

Gender: M / F (circle one)

Height:

Weight:

Year in School: Freshman/Sophomore/Junior/Senior (circle one)

Years playing soccer:

Years heading the ball in practices and games:

Approximately how many times do you head the ball in a practice or game?

What position do you primarily play?

\section{INJURY HISTORY}

1. Have you had a lower extremity injury within the past six months? Yes/No If yes, please explain:

2. Have you had an upper extremity injury within the past six months? Yes/No If yes, please explain:

3. Have you had a head injury within the past six months (This includes concussions, having your bell rung, etc.)? Yes/No

If yes, please explain:

4. Have you had any neck injuries in the past six months? Yes/No

If yes, please explain: 


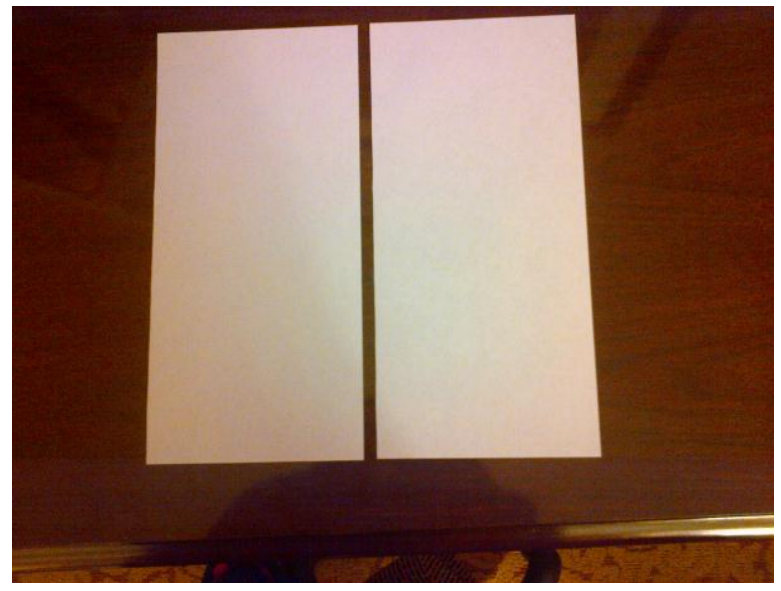

Cut contact and developer sheet

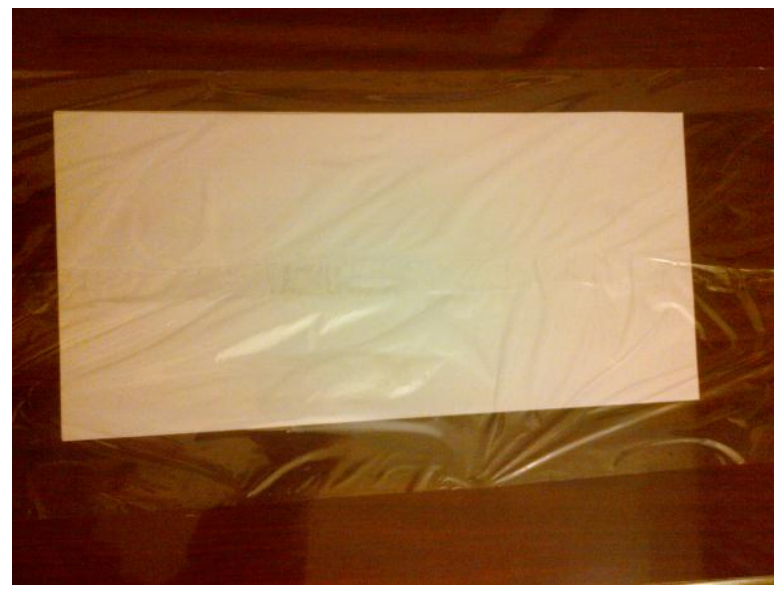

Films placed together and encased in plastic wrap

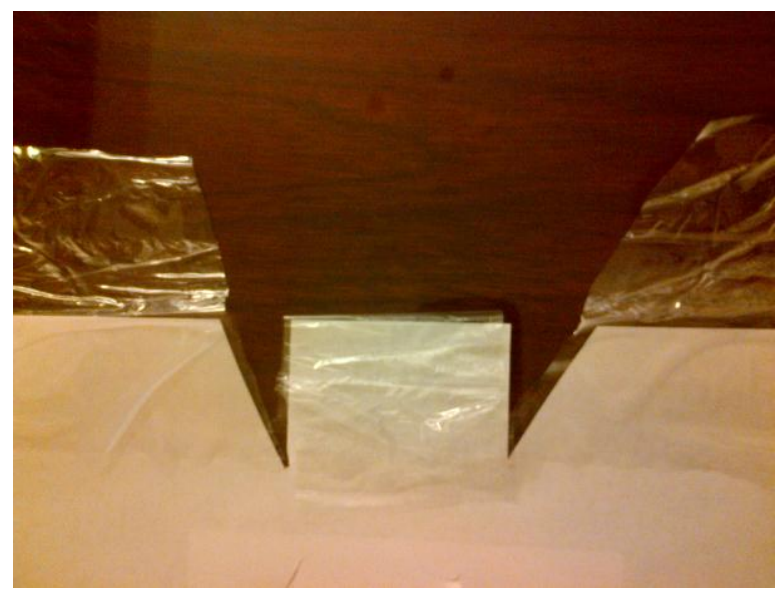

Triangles cut to allow for a better fit over the top of the head 


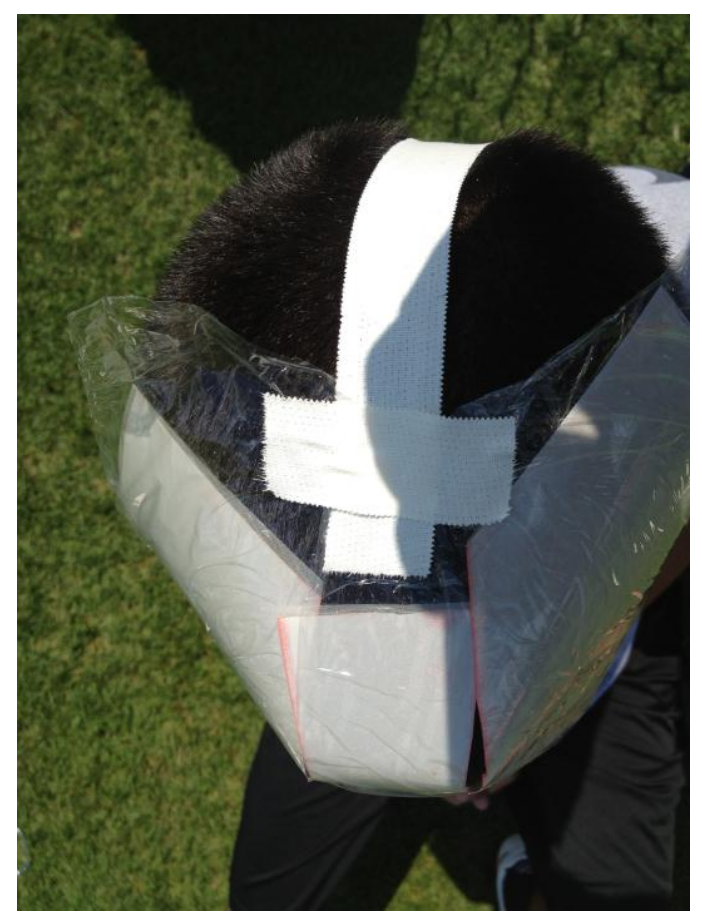

Top View

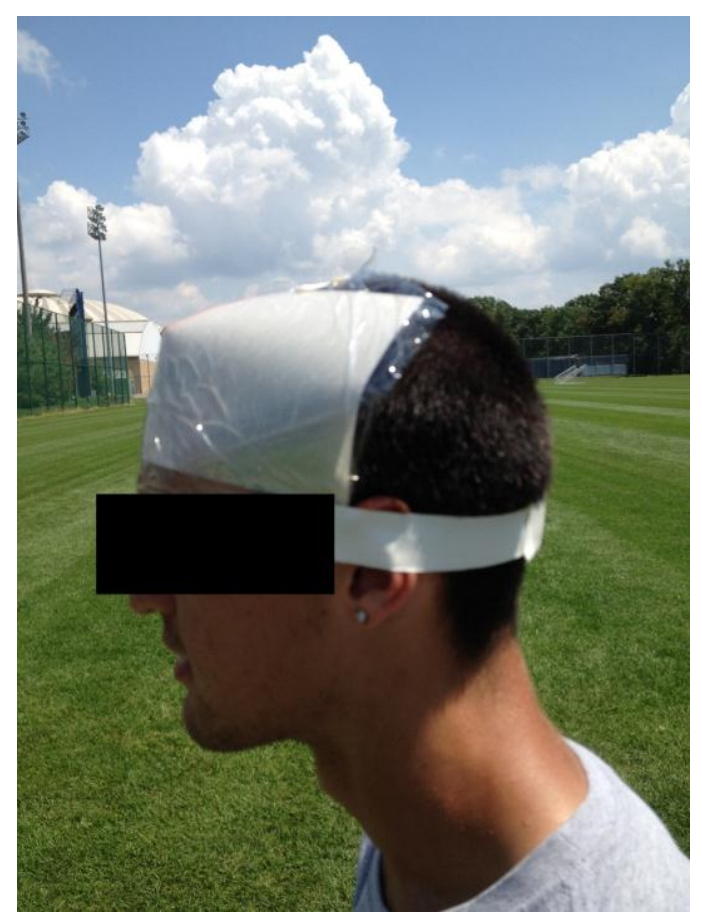

Side View

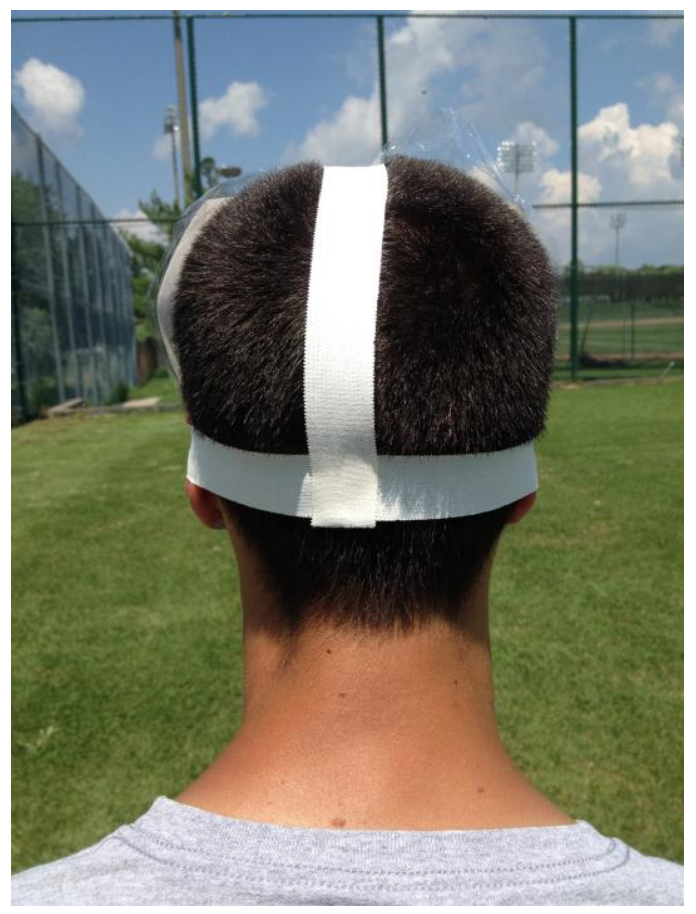

Rear View

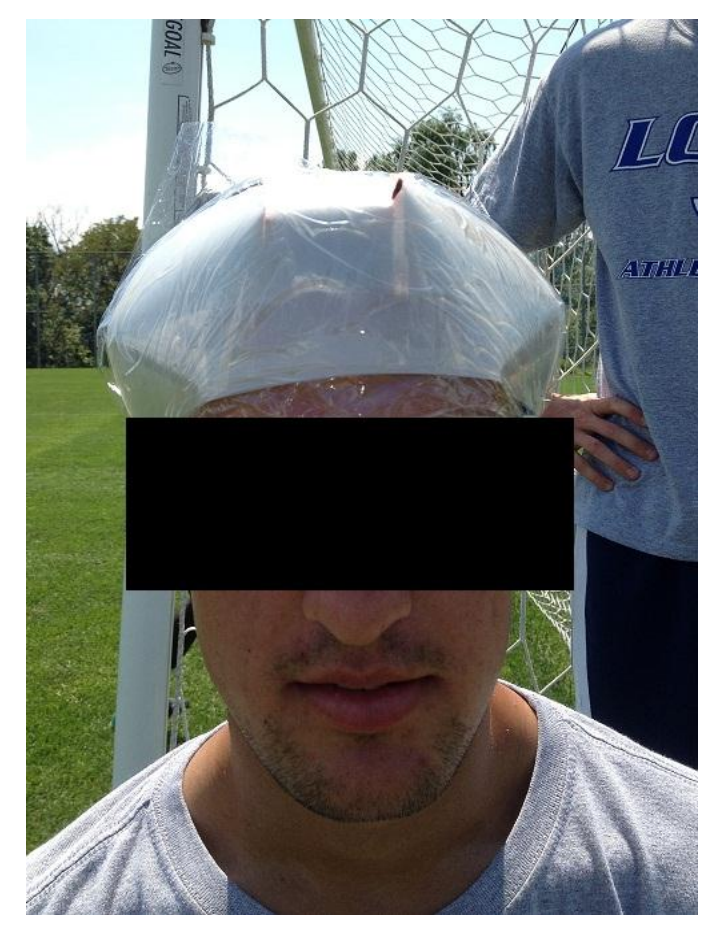

Front View 
Figure C3. Goal kick

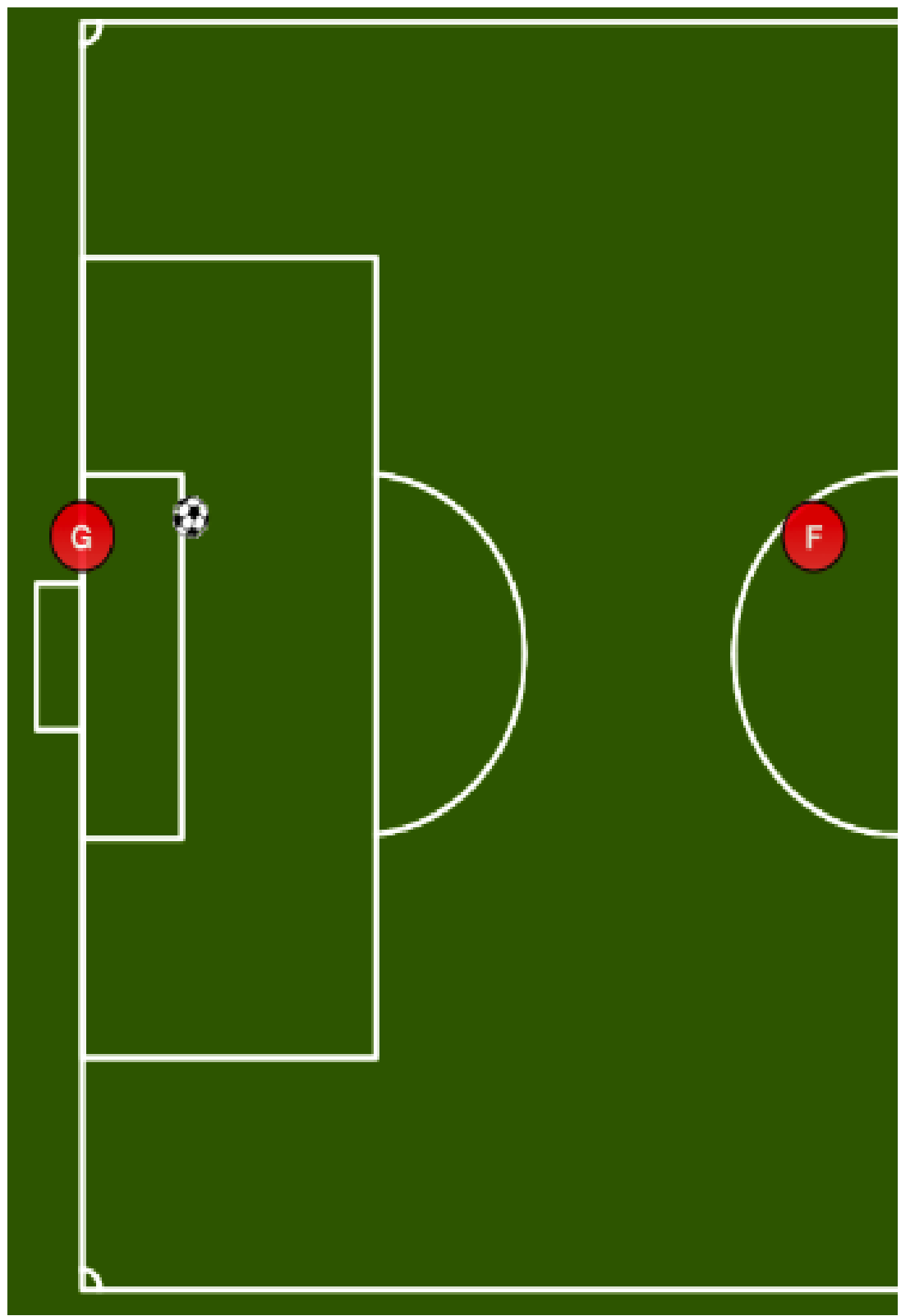

- Header will stand at halfway line

- Kicker will kick ball from goal box line towards header

- Header will head the ball as they would in a game 


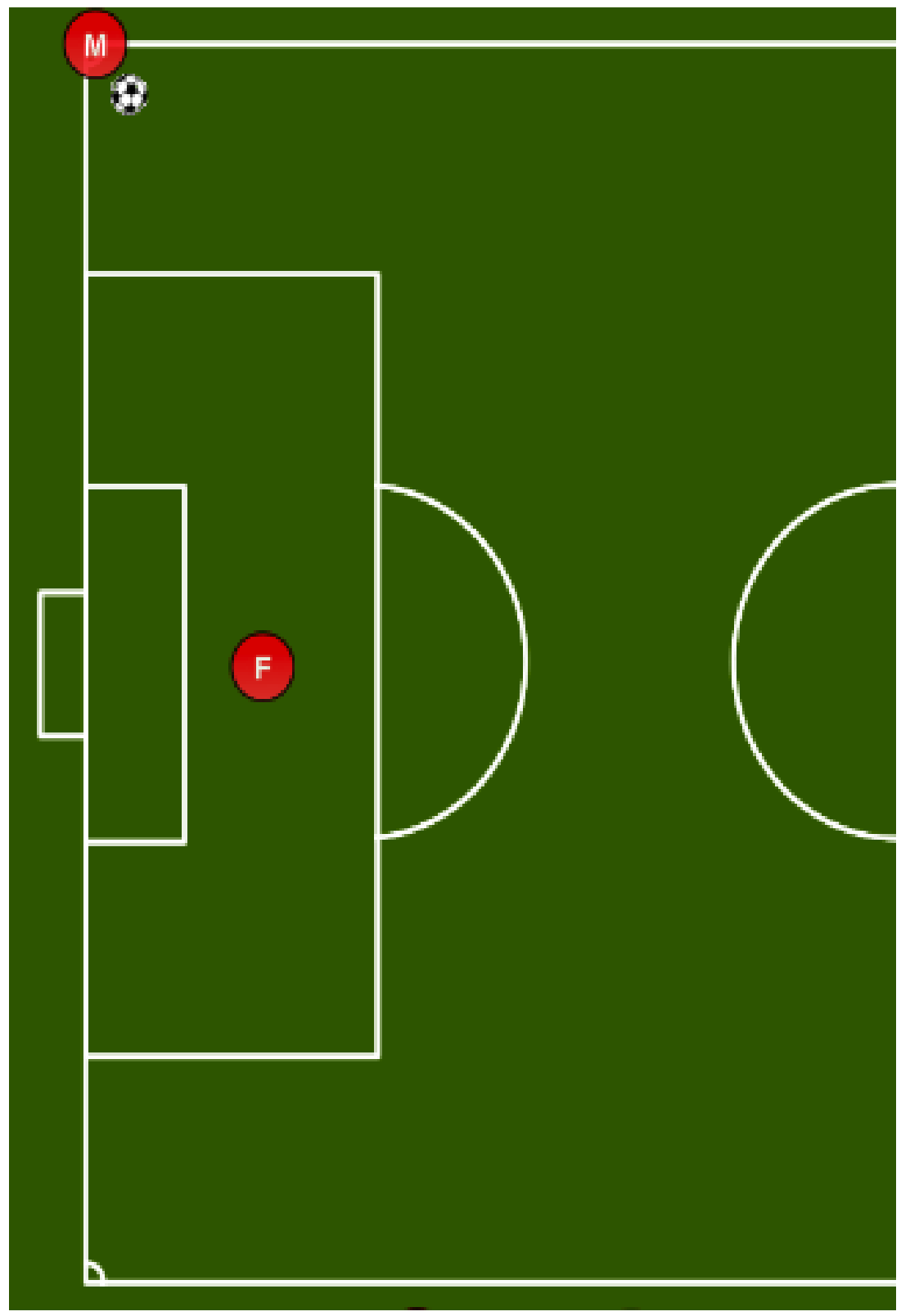

- Header will stand in front of goal

- Kicker will kick ball from corner of field towards header

- Header will head the ball to either a)try to score a goal or b)deflect the ball 


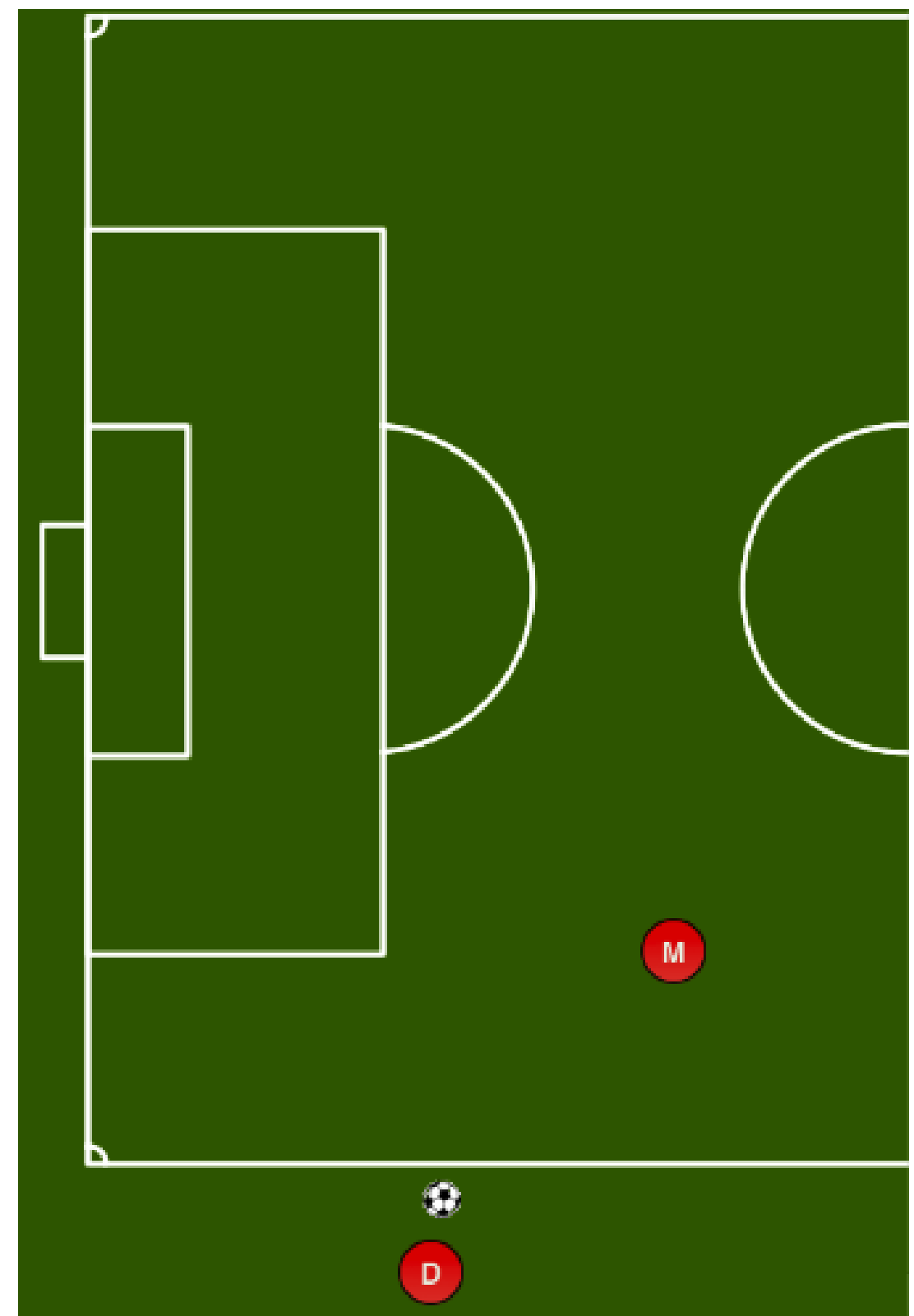

- Header will stand 15 yards in-field from sideline

- Thrower will throw ball in from sideline using proper technique

- Header will head ball as they would in a game 


\section{APPENDIX D}

\section{ADDITIONAL RESULTS}

Table D1. Subject 1 Results for the Three Heading Scenarios

\begin{tabular}{|c|c|c|c|c|c|c|c|c|c|c|c|c|}
\hline $\begin{array}{l}\text { CORNER } \\
\text { KICK }\end{array}$ & Mass (lb) & $\begin{array}{l}\text { Speed } \\
(\mathrm{mph})\end{array}$ & $\begin{array}{l}\text { Avg. } \\
\text { Pressure } \\
\text { (PSI) }\end{array}$ & $\begin{array}{c}\text { Min. } \\
\text { Pressure } \\
\text { (PSI) }\end{array}$ & $\begin{array}{c}\text { Max. } \\
\text { Pressure } \\
\text { (PSI) }\end{array}$ & $\begin{array}{c}\text { Std. } \\
\text { Deviation }\end{array}$ & $\begin{array}{c}\text { Contact } \\
\text { Area } \\
\left(\mathrm{in}^{2}\right)\end{array}$ & $\begin{array}{l}\text { Total } \\
\text { Area } \\
\left(\text { in }^{2}\right)\end{array}$ & $\begin{array}{c}\text { Force } \\
\text { (lbf) }\end{array}$ & $\begin{array}{l}\text { Momentum } \\
\left(\mathrm{lb} / \mathrm{in}^{2}\right)\end{array}$ & Delta T (s) & Kin. Energy \\
\hline 1 & 1 & 43 & 49.71 & 25.57 & 85 & 15.31 & 10.09 & 204 & 501.48 & 1.967306 & 0.003923 & 746.966301 \\
\hline 2 & 1 & 48 & 52.16 & 28.57 & 85 & 16.72 & 10.61 & 204 & 553.7 & 2.196062 & 0.003966 & 930.778993 \\
\hline 3 & 1 & 38 & 49.52 & 28.57 & 85 & 15.09 & 9.5 & 204 & 470.36 & 1.738549 & 0.003696 & 583.352806 \\
\hline 4 & 1 & 54 & 53.66 & 28.57 & 85 & 16.16 & 17.34 & 204 & 930.38 & 2.470570 & 0.002655 & 1178.01716 \\
\hline 5 & 1 & 48 & 50.89 & 28.57 & 85 & 14.9 & 11.79 & 204 & 599.88 & 2.196062 & 0.003661 & 930.778993 \\
\hline \multicolumn{13}{|l|}{$\begin{array}{l}\text { THROW- } \\
\text { IN }\end{array}$} \\
\hline 1 & 1 & 26 & 49.02 & 28.57 & 85 & 14.71 & 11.62 & 204 & 569.42 & 1.189534 & 0.002089 & 273.093142 \\
\hline 2 & 1 & 31 & 47.28 & 28.57 & 85 & 13.42 & 9.47 & 204 & 447.62 & 1.418290 & 0.003169 & 388.228564 \\
\hline 3 & 1 & 28 & 51.4 & 28.57 & 85 & 15.98 & 12.01 & 204 & 617.3 & 1.281036 & 0.002075 & 316.723407 \\
\hline 4 & 1 & 28 & 49.56 & 28.57 & 85 & 14.45 & 14.85 & 204 & 736.03 & 1.281036 & 0.001740 & 316.723407 \\
\hline 5 & 1 & 30 & 47.5 & 28.57 & 85 & 13.98 & 1023 & 204 & 486.01 & 1.372539 & 0.002824 & 363.585544 \\
\hline \multicolumn{13}{|l|}{$\begin{array}{l}\text { GOAL } \\
\text { KICK }\end{array}$} \\
\hline 1 & 1 & 57 & 50.63 & 28.57 & 85 & 15.83 & 13.46 & 204 & 681.5 & 2.607824 & 0.003827 & 1312.54381 \\
\hline 2 & 1 & 54 & 54.67 & 28.57 & 85 & 16.51 & 16.22 & 204 & 886.84 & 2.470570 & 0.002786 & 1178.01716 \\
\hline 3 & 1 & 38 & 54.85 & 28.57 & 85 & 16.95 & 19.52 & 204 & $1,070.48$ & 1.738549 & 0.001624 & 583.352806 \\
\hline 4 & 1 & 39 & 55.59 & 28.57 & 85 & 16.51 & 14.88 & 204 & 827.37 & 1.784301 & 0.002157 & 614.459569 \\
\hline 5 & 1 & - & - & - & - & - & - & - & - & & & \\
\hline
\end{tabular}

KEY: Avg. PSI= average pounds per square inch; Min PSI= minimum pounds per square inch; Max PSI= maximum pounds per square inch Delta $\mathrm{T}=$ change in time; Kin. En = Kinetic Energy 
Table D2. Subject 2 Results for the Three Heading Scenarios

\begin{tabular}{|c|c|c|c|c|c|c|c|c|c|c|c|c|}
\hline $\begin{array}{l}\text { CORNER } \\
\text { KICK }\end{array}$ & Mass (lb) & $\begin{array}{l}\text { Speed } \\
(\mathrm{mph})\end{array}$ & $\begin{array}{c}\text { Avg. } \\
\text { Pressure } \\
\text { (PSI) }\end{array}$ & $\begin{array}{c}\text { Min. } \\
\text { Pressure } \\
\text { (PSI) }\end{array}$ & $\begin{array}{c}\text { Max. } \\
\text { Pressure } \\
\text { (PSI) }\end{array}$ & $\begin{array}{c}\text { Std. } \\
\text { Deviation }\end{array}$ & $\begin{array}{c}\text { Contact } \\
\text { Area }\left(\text { in }^{2}\right)\end{array}$ & $\begin{array}{c}\text { Total } \\
\text { Area }\left(\mathrm{in}^{2}\right)\end{array}$ & $\begin{array}{c}\text { Force } \\
\text { (lbf) }\end{array}$ & $\begin{array}{l}\text { Momentum } \\
\quad(\mathrm{lb} / \mathrm{in} 2)\end{array}$ & $\begin{array}{c}\text { Delta } \mathrm{T} \\
(\mathrm{s})\end{array}$ & Kin. En. \\
\hline 1 & 1 & 40 & 49.58 & 28.57 & 85 & 15.16 & 12.28 & 204 & 608.9 & 1.830051813 & 0.003006 & 646.3743 \\
\hline 2 & 1 & 38 & 48.53 & 28.57 & 85 & 14.36 & 12.02 & 204 & 583.05 & 1.738549223 & 0.002982 & 1166.706 \\
\hline 3 & 1 & 41 & 51.89 & 28.57 & 85 & 15.52 & 16.33 & 204 & 847.26 & 1.875803109 & 0.002214 & 2037.291 \\
\hline 4 & 1 & 37 & 52.27 & 28.57 & 85 & 15.89 & 16.32 & 204 & 852.74 & 1.692797927 & 0.001985 & 2212.216 \\
\hline 5 & 1 & 42 & 55.18 & 28.57 & 85 & 15.65 & 18.45 & 204 & $1,018.21$ & 1.921554404 & 0.001887 & 3563.138 \\
\hline \multicolumn{13}{|l|}{$\begin{array}{l}\text { THROW- } \\
\text { IN }\end{array}$} \\
\hline 1 & 1 & 29 & 46.33 & 28.57 & 85 & 13.61 & 11.01 & 204 & 510.99 & 1.326787565 & 0.002597 & 339.7505 \\
\hline 2 & 1 & 29 & 47.13 & 28.57 & 85 & 13.69 & 11.77 & 204 & 554.75 & 1.326787565 & 0.002392 & 679.501 \\
\hline 3 & 1 & 26 & 48.28 & 28.57 & 85 & 13.91 & 12.75 & 204 & 615.62 & 1.189533679 & 0.001932 & 819.2794 \\
\hline 4 & 1 & 27 & 50.04 & 28.57 & 85 & 14.68 & 12.4 & 204 & 620.67 & 1.235284974 & 0.00199 & 1178.017 \\
\hline 5 & 1 & 28 & 45.76 & 28.57 & 85 & 14.15 & 12.36 & 204 & 565.6 & 1.281036269 & 0.002265 & 1583.617 \\
\hline \multicolumn{13}{|l|}{$\begin{array}{l}\text { GOAL } \\
\text { KICK }\end{array}$} \\
\hline 1 & 1 & 46 & 49.68 & 28.57 & 85 & 14.82 & 10.1 & 204 & 502.04 & 2.104559585 & 0.004192 & 854.83 \\
\hline 2 & 1 & 46 & 51.37 & 28.57 & 85 & 14.93 & 18.09 & 204 & 929.13 & 2.104559585 & 0.002265 & 1709.66 \\
\hline 3 & 1 & 53 & 53.18 & 28.57 & 85 & 15.71 & 16.88 & 204 & 897.52 & 2.424818653 & 0.002702 & 3404.373 \\
\hline 4 & 1 & 49 & 49.94 & 28.57 & 85 & 14.42 & 16.21 & 204 & 809.57 & 2.241813472 & 0.002769 & 3879.862 \\
\hline 5 & & - & - & - & - & - & - & - & - & & & \\
\hline
\end{tabular}

KEY: Avg. PSI= average pounds per square inch; Min PSI= minimum pounds per square inch; Max PSI= maximum pounds per square inch Delta $\mathrm{T}=$ change in time; Kin. En = Kinetic Energy 
Table D3. Subject 3 Results for the Three Heading Scenarios

\begin{tabular}{|c|c|c|c|c|c|c|c|c|c|c|c|c|}
\hline $\begin{array}{l}\text { CORNER } \\
\text { KICK }\end{array}$ & Mass (lb) & $\begin{array}{l}\text { Speed } \\
(\mathrm{mph})\end{array}$ & $\begin{array}{l}\text { Avg. } \\
\text { Pressure } \\
\text { (PSI) }\end{array}$ & $\begin{array}{l}\text { Min. } \\
\text { Pressure } \\
\text { (PSI) }\end{array}$ & $\begin{array}{c}\text { Max. } \\
\text { Pressure } \\
\text { (PSI) }\end{array}$ & $\begin{array}{c}\text { Std. } \\
\text { Deviation }\end{array}$ & $\begin{array}{c}\text { Contact } \\
\text { Area } \\
\left(\mathrm{in}^{2}\right)\end{array}$ & $\begin{array}{l}\text { Total } \\
\text { Area } \\
\left(\mathrm{in}^{2}\right)\end{array}$ & $\begin{array}{c}\text { Force } \\
\text { (lbf) }\end{array}$ & $\begin{array}{c}\text { Momentum } \\
\left(\mathrm{lb} / \mathrm{in}^{2}\right)\end{array}$ & Delta T (s) & Kin. En. \\
\hline 1 & 1 & 41 & 48.52 & 28.57 & 85 & 14.36 & 12.37 & 204 & 600.42 & 1.875803109 & 0.00312415 & 679.097 \\
\hline 2 & 1 & 55 & 51.75 & 28.57 & 85 & 15.46 & 14.55 & 204 & 752.88 & 2.516321244 & 0.00334226 & 1222.051 \\
\hline 3 & 1 & 39 & 51.55 & 28.57 & 85 & 16.97 & 11.41 & 204 & 587.99 & 1.784300518 & 0.00303458 & 614.4596 \\
\hline 4 & 1 & 47 & 49.82 & 28.57 & 85 & 15.33 & 14.82 & 204 & 738.46 & 2.150310881 & 0.00291189 & 892.4005 \\
\hline 5 & 1 & 39 & 48.86 & 28.57 & 85 & 14.56 & 15.39 & 204 & 752.14 & 1.784300518 & 0.0023723 & 614.4596 \\
\hline \multicolumn{13}{|l|}{$\begin{array}{l}\text { THROW- } \\
\text { IN }\end{array}$} \\
\hline 1 & 1 & 30 & 48.97 & 28.57 & 85 & 15.69 & 7.07 & 204 & 346.34 & 1.37253886 & 0.00396298 & 363.5855 \\
\hline 2 & 1 & 29 & 48.57 & 28.57 & 85 & 15.3 & 11.65 & 204 & 565.7 & 1.326787565 & 0.00234539 & 339.7505 \\
\hline 3 & 1 & 29 & 49.45 & 28.57 & 85 & 14.36 & 13.5 & 204 & 667.54 & 1.326787565 & 0.00198758 & 339.7505 \\
\hline 4 & 1 & 29 & 54.04 & 28.57 & 85 & 17.01 & 14.28 & 204 & 771.59 & 1.326787565 & 0.00171955 & 339.7505 \\
\hline 5 & 1 & 28 & 52.19 & 28.57 & 85 & 15.9 & 12.77 & 204 & 666.63 & 1.281036269 & 0.00192166 & 316.7234 \\
\hline \multicolumn{13}{|l|}{$\begin{array}{l}\text { GOAL } \\
\text { KICK }\end{array}$} \\
\hline 1 & 1 & 46 & 45.84 & 28.57 & 85 & 13.27 & 11.79 & 204 & 540.46 & 2.104559585 & 0.00389402 & 854.83 \\
\hline 2 & 1 & 48 & 53.17 & 28.57 & 85 & 16.32 & 19.43 & 204 & $1,033.09$ & 2.196062176 & 0.00212572 & 930.779 \\
\hline 3 & 1 & 41 & 50.82 & 28.57 & 85 & 14.94 & 15.71 & 204 & 798.29 & 1.875803109 & 0.00234978 & 679.097 \\
\hline 4 & 1 & 43 & 49.69 & 28.57 & 85 & 13.97 & 14.91 & 204 & 740.65 & 1.967305699 & 0.00265619 & 746.9663 \\
\hline$\underline{5}$ & 1 & - & - & - & - & - & - & - & - & & & \\
\hline
\end{tabular}

KEY: Avg. PSI= average pounds per square inch; Min PSI= minimum pounds per square inch; Max PSI= maximum pounds per square inch; Delta $\mathrm{T}=$ change in time; Kin. En = Kinetic Energy 
Figure D1. Corner Kicks

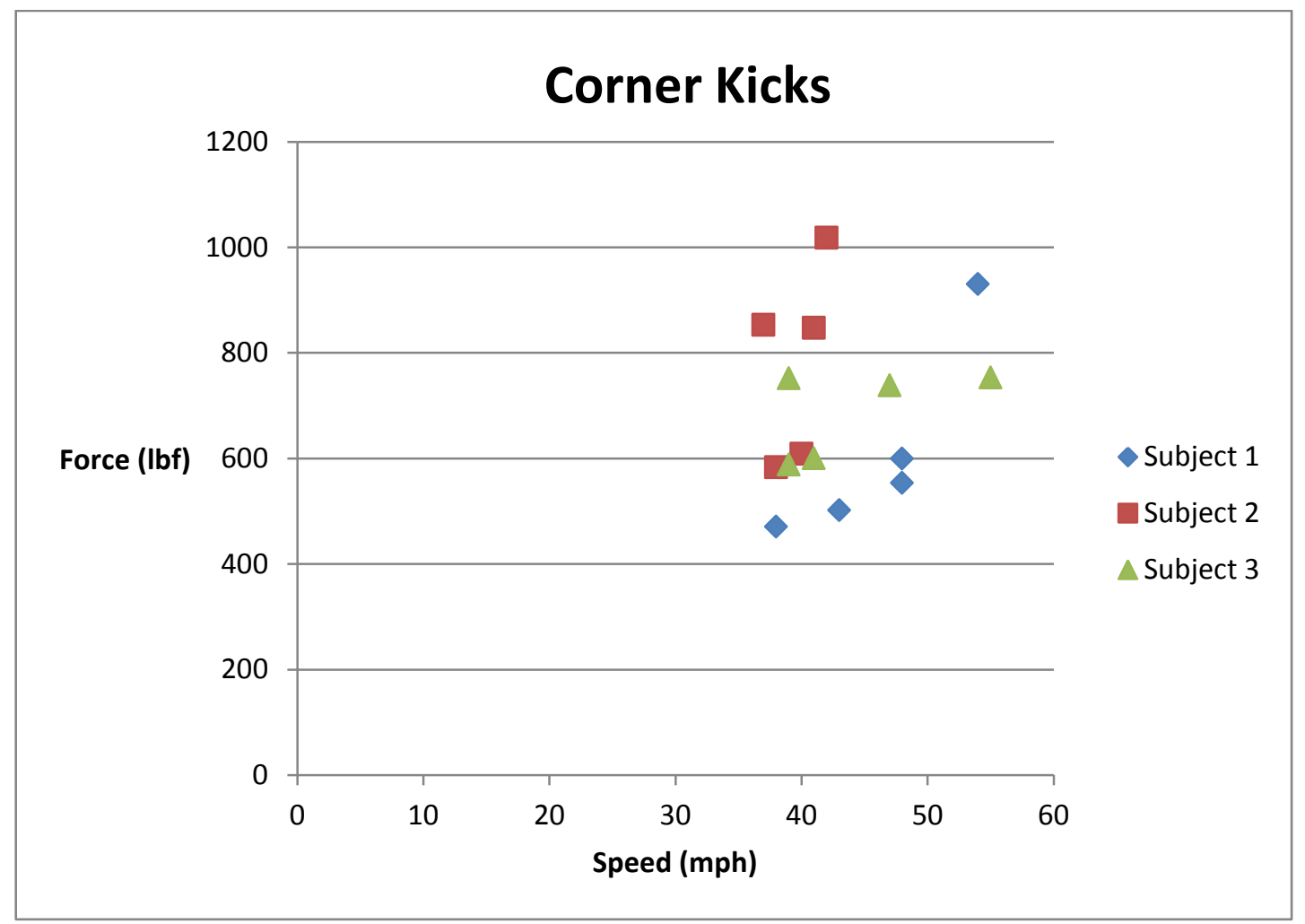


Figure D2. Throw In

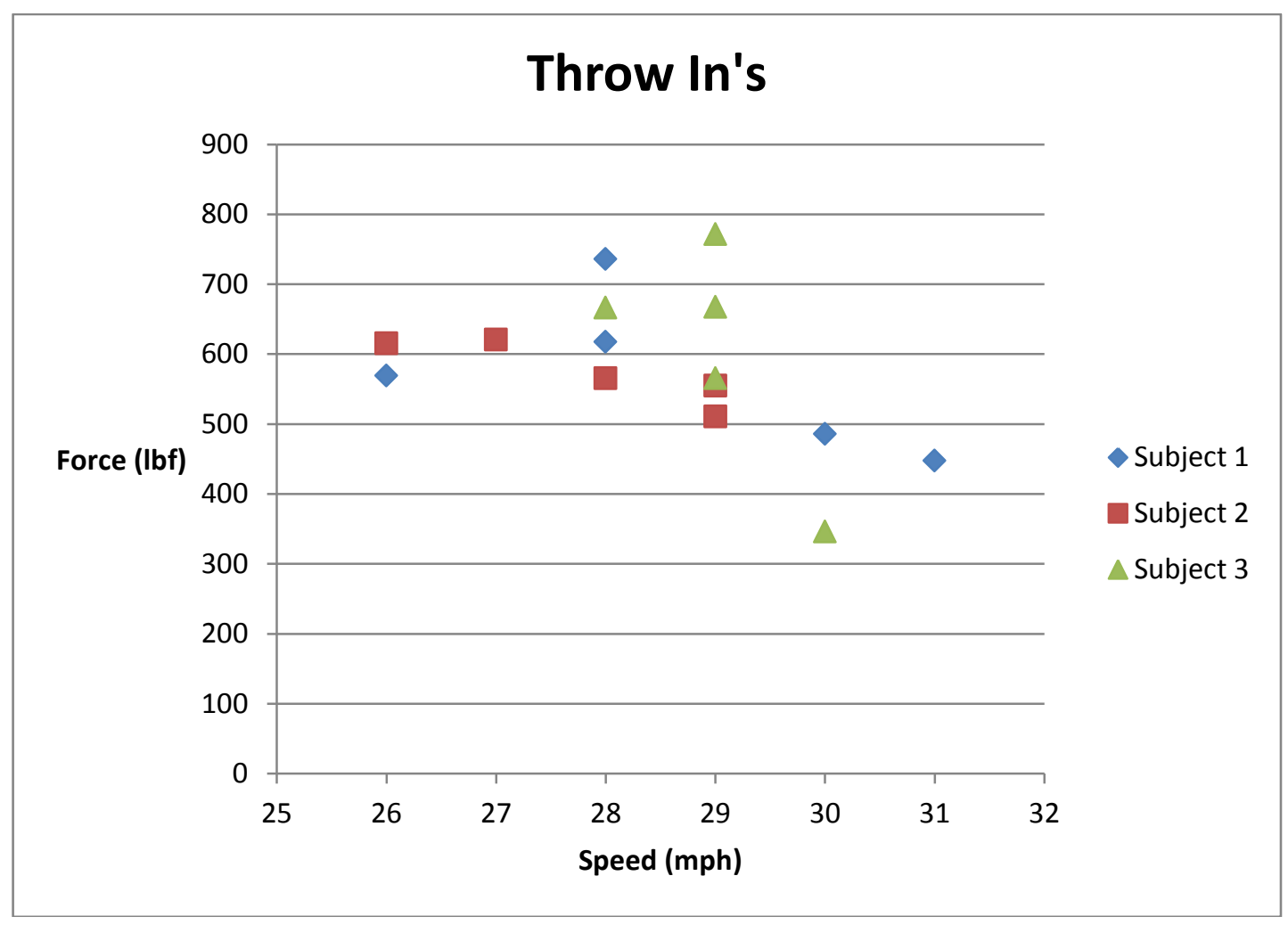


Figure D3. Goal Kicks

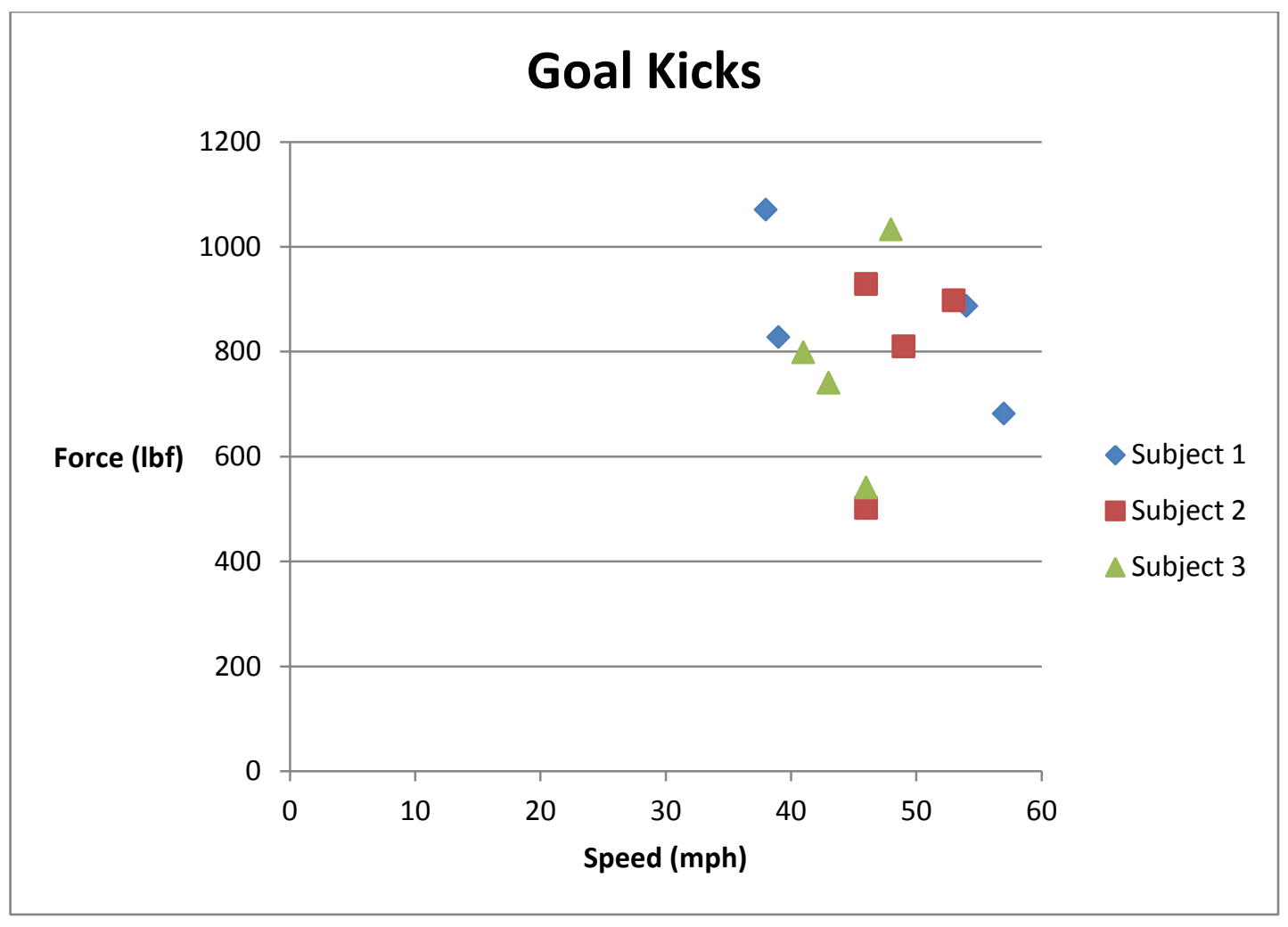


Figure D4. Ball Speed Results

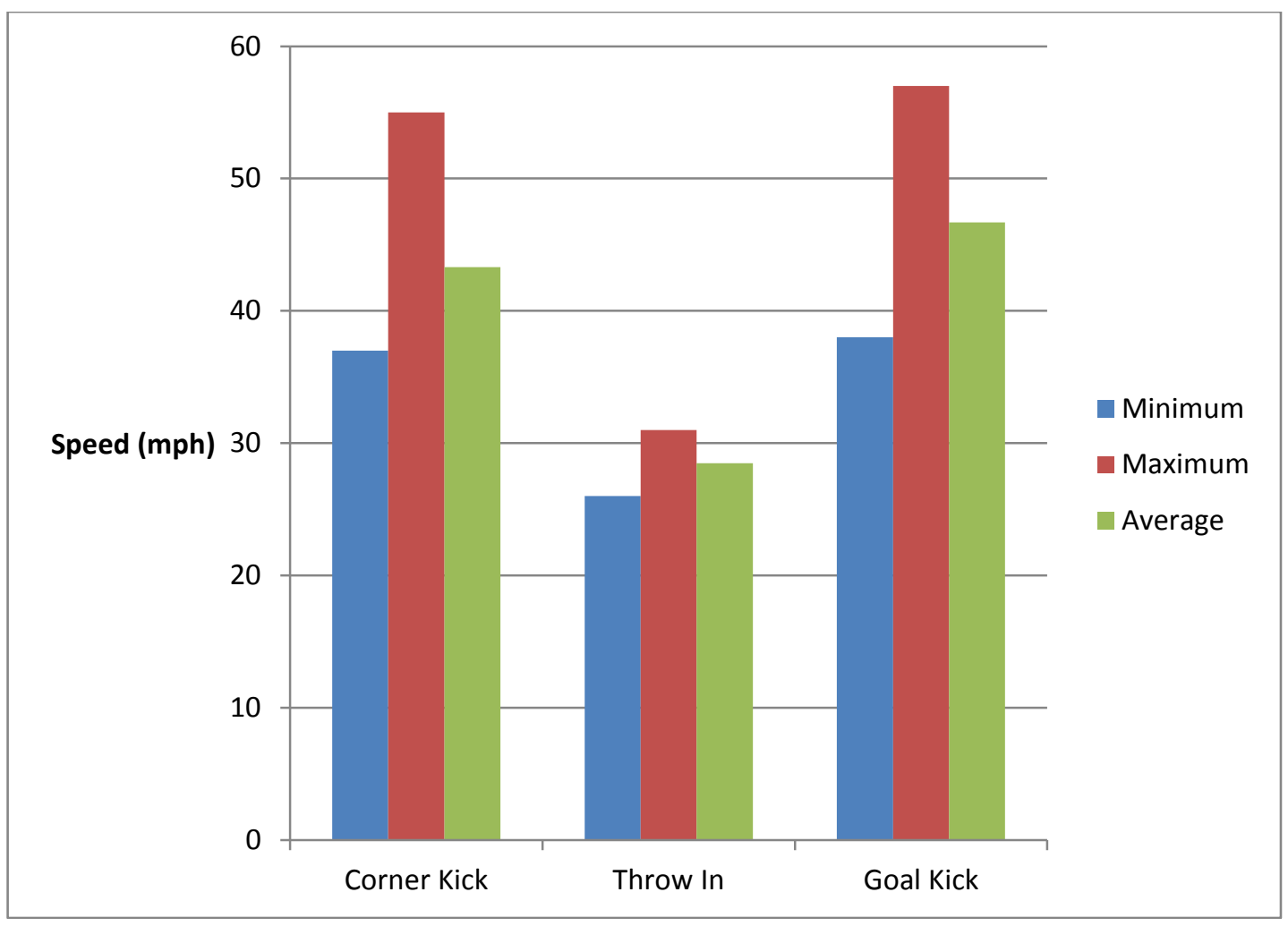


Figure D5. Force Results

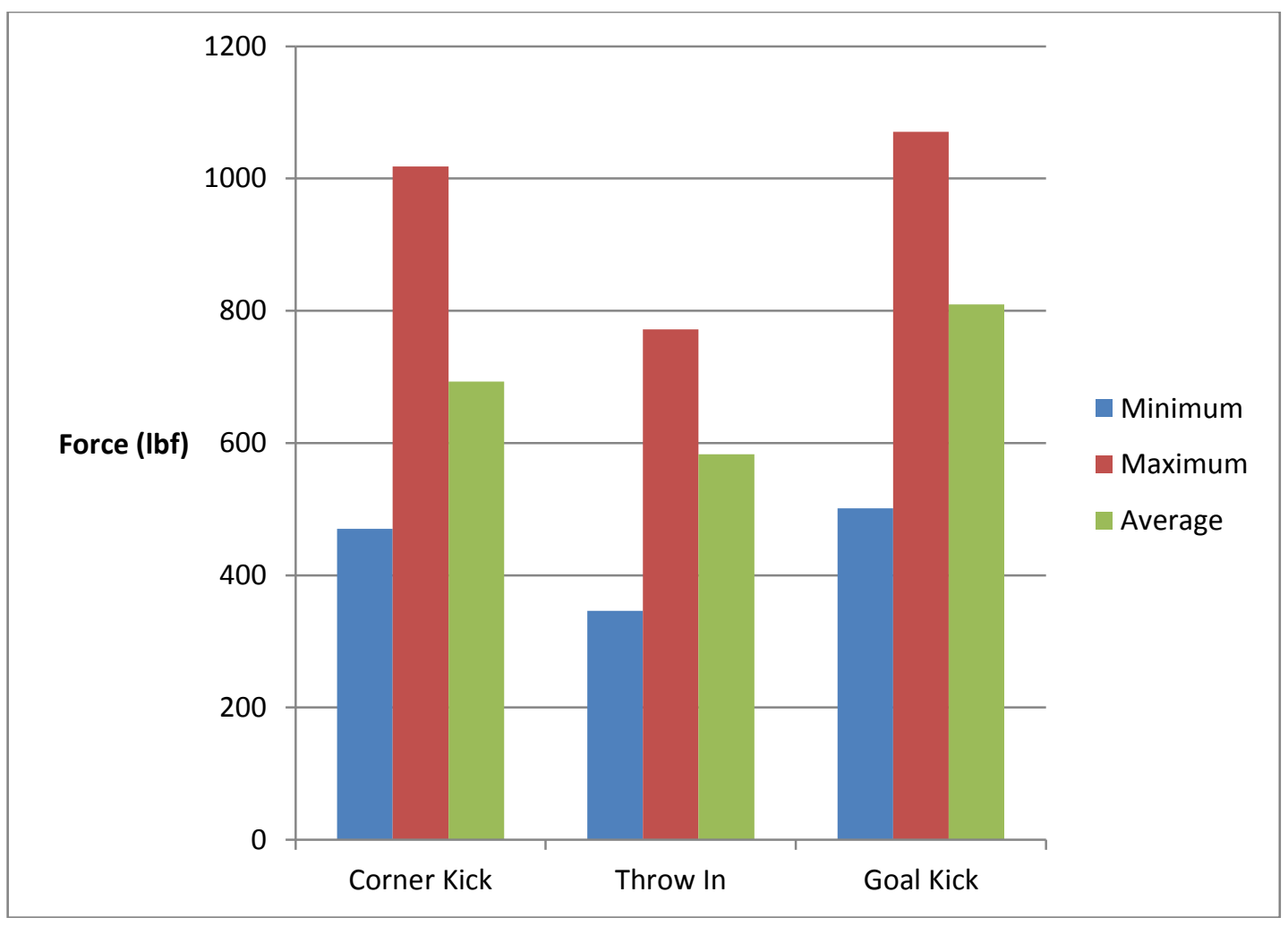




\section{APPENDIX E}

\section{RECOMMENDATIONS FOR FUTURE RESEARCH}

1. Use a larger sample size of soccer players that are considered "headers".

2. Test pressure film samples of different sensitivity prior to purchase to ensure that the film is not hyposensitive or hypersensitive. This will allow for more accurate results.

3. Wrap pressure film in plastic wrap as close to the time of the study as possible.

4. Ensure that scanned pressure film image is cropped to the correct size before analysis.

5. Consider use of a high-speed video camera for slow motion analysis to determine the velocity of the ball and the player at the time of impact. Finding the differential will provide a more accurate representation of momentum and duration of impact.

6. Consider use of mouth guards fitted with accelerometers to measure acceleration/deceleration of the head during impact when heading soccer balls. 


\section{ADDITIONAL REFERENCES}

17. Giza CC, Hovda DA. The neurometabolic cascade of concussion. J Athl Train. 2001;36(3):228-35.

18. DeLellis SM, Kane S, Katz K. The neurometabolic cascade and implication of mTBI: mitigating risk to the SOF community. J Spec Operation Med. 2009; 9(4)36-42.

19. Powell JW. Cerebral concussion: causes, effects and risks in sports. J Athl Train. 2001;36(3):307-11.

20. Gordon KE, Dooley JM, Wood EP. Descriptive epidemiology on concussion. Pediatr Neurol. 2006;34:376-78.

21. Shewchenko N, Withnall C, Keown M et al. Heading in football. Part 2:

biomechanics of ball heading and head response. Br J Sports Med. 2005;36:i26i32.

22. Rutherford A, Stephens R, Potter D. The neuropsychology of heading and head trauma in association football (soccer): A review. Neuropsychology Review. 2003;13(3):153-79.

23. Tysvaer AT. Head and neck injuries in soccer. Impact of minor trauma. Sports Med. 1992;14(3):200-13.

24. Jordan Se, Green GA, Galanty HL et al. Acute and chronic brain injury in United States national team soccer players. Am J Sports Med. 1996;24:205-10. 